\title{
Neuronal generator patterns at scalp elicited by lateralized aversive pictures reveal consecutive stages of motivated attention
}

\author{
Jürgen Kayser $^{\text {a,b,* }}$, Craig E. Tenke ${ }^{\mathrm{a}, \mathrm{b}}$, Karen S. Abraham ${ }^{\mathrm{a}}$, Daniel M. Alschuler ${ }^{\text {a }}$, Jorge E. Alvarenga ${ }^{\mathrm{a}}$, \\ Jamie Skipper ${ }^{c}$, Virginia Warner ${ }^{\mathrm{c}, \mathrm{d}}$, Gerard E. Bruder ${ }^{\mathrm{a}, \mathrm{b}}$, Myrna M. Weissman ${ }^{\mathrm{b}, \mathrm{c}, \mathrm{d}}$ \\ a Division of Cognitive Neuroscience, New York State Psychiatric Institute, New York, NY, United States \\ b Department of Psychiatry, Columbia University College of Physicians and Surgeons, New York, NY, United States \\ c Division of Epidemiology, New York State Psychiatric Institute, New York, NY, United States \\ d Mailman School of Public Health, Columbia University, New York, NY, United States
}

\section{A R T I C L E I N F O}

\section{Article history:}

Received 2 March 2016

Revised 21 April 2016

Accepted 24 May 2016

Available online $\mathrm{xxxx}$

\section{Keywords:}

Event-related potential (ERP)

Current source density (CSD)

Principal components analysis (PCA)

Source localization

Late positive potential (LPP)

Emotional lateralization

\begin{abstract}
A B S T R A C T
Event-related potential (ERP) studies have provided evidence for an allocation of attentional resources to enhance perceptual processing of motivationally salient stimuli. Emotional modulation affects several consecutive components associated with stages of affective-cognitive processing, beginning as early as $100-200 \mathrm{~ms}$ after stimulus onset. In agreement with the notion that the right parietotemporal region is critically involved during the perception of arousing affective stimuli, some ERP studies have reported asymmetric emotional ERP effects. However, it is difficult to separate emotional from non-emotional effects because differences in stimulus content unrelated to affective salience or task demands may also be associated with lateralized function or promote cognitive processing. Other concerns pertain to the operational definition and statistical independence of ERP component measures, their dependence on an EEG reference, and spatial smearing due to volume conduction, all of which impede the identification of distinct scalp activation patterns associated with affective processing. Building on prior research using a visual half-field paradigm with highly controlled emotional stimuli (pictures of cosmetic surgery patients showing disordered [negative] or healed [neutral] facial areas before or after treatment), 72channel ERPs recorded from 152 individuals (ages 13-68 years; 81 female) were transformed into reference-free current source density (CSD) waveforms and submitted to temporal principal components analysis (PCA) to identify their underlying neuronal generator patterns. Using both nonparametric randomization tests and repeated measures ANOVA, robust effects of emotional content were found over parietooccipital regions for CSD factors corresponding to N2 sink ( $212 \mathrm{~ms}$ peak latency), P3 source ( $385 \mathrm{~ms}$ ) and a late centroparietal source (630 ms), all indicative of greater positivity for negative than neutral stimuli. For the N2 sink, emotional effects were right-lateralized and modulated by hemifield, with larger amplitude and asymmetry for left hemifield (right hemisphere) presentations. For all three factors, more positive amplitudes at parietooccipital sites were associated with increased ratings of negative valence and greater arousal. Distributed inverse solutions of the CSDPCA-based emotional effects implicated a sequence of maximal activations in right occipitotemporal cortex, bilateral posterior cingulate cortex, and bilateral inferior temporal cortex. These findings are consistent with hierarchical activations of the ventral visual pathway reflecting subsequent processing stages in response to motivationally salient stimuli.
\end{abstract}

(c) 2016 Elsevier Inc. All rights reserved.

\section{Introduction}

The detection of stimulus significance is a critical mechanism for survival, presumably constituted by two basic motivational systems mediating appetitive and defensive behavior (e.g., Bradley, 2009; Lang et al., 1998a). The necessary operations involve interactions between affective

* Corresponding author at: Division of Cognitive Neuroscience, New York State Psychiatric Institute, Unit 50, 1051 Riverside Drive, New York, NY 10032, United States.

E-mail address: kayserj@nyspi.columbia.edu (J. Kayser). and cognitive processing systems of the brain (e.g., Pessoa, 2008), which reach conscious awareness in the hierarchy of information processing when the products of affective and cognitive computations enter into working memory (e.g., LeDoux, 1989). Electrophysiological measures of ongoing brain activity, particularly event-related potentials (ERPs), are ideally suited to characterize consecutive stages of affective processing with millisecond temporal resolution, and ERP research with human populations has made considerable progress in this regard over the last two decades (e.g., see reviews by Hajcak et al., 2012; Olofsson et al., 2008). The most consistent finding has been an increased positivity to 
emotional (pleasant or unpleasant) compared to neutral pictures, often termed the late positive potential (LPP), which emerges around 200$300 \mathrm{~ms}$ after stimulus onset and affects several subcomponents of the late positive complex, including P3 and slow wave (e.g., Johnston et al., 1986). A broad topographical LPP maximum is typically observed over mid-parietal and centro-parietal scalp locations, with its amplitude closely covarying with the perceived arousal properties of a given stimulus (e.g., Cuthbert et al., 2000; Schupp et al., 2000), suggesting an increased allocation of attentional resources to stimuli that intrinsically engage motivational brain circuits (e.g., Bradley, 2009). Valence properties have less consistently been linked to the LPP; however, pictures of negative rather than positive affect tend to elicit a greater LPP ("negativity bias"; e.g., Ito et al., 1998b). As this may be due to their higher intrinsic motivational value, a systematic control of arousal and valence stimulus properties is an essential requirement for an interpretation of these findings (Olofsson et al., 2008). For example, no negativity bias is observed when unpleasant and pleasant pictures are matched for motivational saliency (Hajcak et al., 2012).

Affective stimulus significance has also been found to modulate earlier ERP components, including P1 (e.g., Pizzagalli et al., 1999; Smith et al., 2003), N1 (e.g., Keil et al., 2002), P2 (e.g., Delplanque et al., 2004) and N2 (e.g., Junghöfer et al., 2001). An ERP difference component, termed early posterior negativity (EPN; Schupp et al., 2003a, 2003b), revealing more negative-going waveforms for emotional than neutral stimuli at about 200-300 ms over bilateral occipital-temporal regions, has attracted considerable research over the last decade (e.g., Foti et al., 2009; Mavratzakis et al., 2016; Thom et al., 2014; Wiens et al., 2011). However, findings for these earlier ERP components that precede the LPP have been less consistent and notably varied with arousal and valence dimensions (see review by Olofsson et al., 2008), which may be in no small part attributable to differences in methodology, including-but not limited to-study paradigm (e.g., passive viewing, stimulus classification, target detection), stimulus characteristics (e.g., faces, scenes, words), EEG montage (e.g., ranging from selected midline sites to 129 sites or more) and reference (e.g., common average, linked mastoids), ERP component definition and measurement (e.g., peak amplitude, integrated time windows, temporal/spatial PCA), signal-to-noise ratio, and sample size. In contrast, emotional LPP effects, which are omnipresent in space (i.e., broad central-parietal topography) and time (i.e., spanning several hundred milliseconds or longer) and withstand habituation (e.g., Codispoti et al., 2007), are evidently too robust to be substantially affected by any differences in methodology.

Most affective ERP studies using visual stimuli have taken advantage of the International Affective Picture System (IAPS; Bradley and Lang, 2007; Lang et al., 2005), which comprises a large and diverse pool of affect-laden color photographs intended to evoke affective reactions, along with normative ratings of pleasure and arousal. While this allows the matching of valence categories for arousal (e.g., by equating the means of pleasant and unpleasant pictures selected for the experiment), other stimulus features, such as luminance, contrast, color, composition, content, complexity or spatial frequency, are often uncontrolled and constitute a possible confound (e.g., Delplanque et al., 2007; Wiens et al., 2011). Differences in physical stimulus properties will profoundly impact on early ERP components (P1, N1), whereas differences in stimulus content (e.g., animate or object) will likely impact on cognitive ERP components (N2, P3), all of which make it harder to separate genuine emotional from cognitive ERP effects. The problem is augmented when the study objectives include hemispheric differences of emotional processing (Kayser et al., 1997). There is ample clinical and experimental evidence indicating a differential involvement of the two hemispheres during affective states and affective processing (e.g., for reviews see Campbell, 1982; Davidson, 1995; Demaree et al., 2005; Gainotti, 1989; Heller, 1993), and observations for non-human primates suggest that emotional asymmetries may even predate human evolution (Lindell, 2013). Liotti and Tucker (1995) proposed that hemispheric asymmetries in corticolimbic interaction arose from the evolution of functional differences involving dorsal (spatial) and ventral (object) processing streams (e.g., Ungerleider and Haxby, 1994), resulting in a lateralized representation and regulation of both motivational and cognitive domains across multiple levels of the brain hierarchy. Notwithstanding the intricate relationship between emotional and cognitive processes, the mere co-existence of hemispheric differences that should be primarily regarded as cognitive functions, most prominently a leftlateralization of language-related processes and a right hemispheric advantage for processing visuospatial stimuli, particularly of faces (e.g., Gainotti, 2015; Springer and Deutsch, 1989), presents a considerable challenge for the experimental separation of emotional from nonemotional lateralized ERP effects.

In three ERP studies (Kayser et al., 1997, 2000, 2001), we have directly addressed this challenge by employing a set of highly controlled stimuli, which largely isolate emotional content (negative valence, high arousal) from other confounding variables. Affective stimuli were intentionally limited to negative valence as this choice constituted the least common denominator of competing models of emotional lateralization (i.e., valence or approach/withdrawal vs. right hemisphere or dominance hypothesis): a right hemispheric advantage for the perception of negative versus neutral stimuli. This was further reinforced by the fact that negative stimuli were more arousing than their neutral counterparts, because right parietal regions are presumed to also mediate autonomic arousal processes (e.g., Heller, 1993). Furthermore, we used a passive viewing hemifield paradigm with separate stimulus presentations to the right or left visual field to directly probe lateralized hemispheric activity (e.g., McKeever, 1986; Young, 1982). For three different samples of healthy adults, we found enhanced P3 and slow wave amplitudes for negative compared to neutral stimuli. Hemispheric asymmetries in emotional processing were restricted to ERP components of the N2-P3 complex, with maximal effects over the right parietotemporal region. The right temporoparietal junction has been recognized as a key cortical region for detecting affective stimulus significance and modulating associated autonomic arousal (e.g., Caltagirone et al., 1989; Gainotti, 1987; Heller, 1993; Tranel and Damasio, 1994) and has since been linked to a brain network involving cortical (anterior insula, anterior cingulate cortex $[\mathrm{ACC}]$ ) and subcortical (amygdala, striatum) structures for detecting emotional and reward saliency (Corbetta and Shulman, 2002; Lutz et al., 2015). Similar right-greater-than-left asymmetries of emotional content for ERP components preceding LPP have been reported by others (e.g., Junghöfer et al., 2001; Keil et al., 2001, 2002), but this has not been a consistent finding or central research objective for the majority of ERP studies using IAPS pictures (Olofsson et al., 2008).

One crucial feature of our affective ERP studies has been the systematic use of temporal principal components analysis (PCA) as a comprehensive approach to obtain unbiased, data-driven measures (e.g., Donchin and Heffley, 1978; Kayser and Tenke, 2003), which allowed an improved characterization of LPP subcomponents and earlier ERPs related to affective picture responsivity. Notwithstanding the recognized merits of multivariate data decomposition approaches for affective ERP research (e.g., Delplanque et al., 2006; Olofsson et al., 2008; Pourtois et al., 2008), these techniques do not resolve the interpretational ambiguity of ERP signals caused by the EEG reference (e.g., Junghöfer et al., 2006a; Kayser and Tenke, 2010) or their spatial smearing due to volume conduction (e.g., Tenke and Kayser, 2012). However, these limitations can be conveniently overcome by incorporating a surface Laplacian, or current source density (CSD; e.g., Perrin et al., 1989), transformation of surface potentials in the data processing pipeline, which renders a unique, reference-free representation of radial current flow (sinks and sources) underlying the scalp-recorded EEG (e.g., Carvalhaes and de Barros, 2015; Nunez and Srinivasan, 2006; Tenke and Kayser, 2012). Compared to ERPs, CSDs provide higher spatial and temporal resolution (i.e., a more distinct time course; Burle et al., 2015). Unlike more complex inverse source localization techniques (e.g., Michel et al., 2004), which are likewise reference-independent, CSDs do not require any additional assumptions 
about neuronal generator location, orientation or distribution, and the complementary use of CSD as a tool for affective neuroscience has been advocated (e.g., Junghöfer et al., 2006a). Contrary to widespread belief, dense electrode arrays (128 sensors or more) are not required as a necessary prerequisite for CSD methods to be useful (e.g., Kayser and Tenke, 2006b, 2015b). Moreover, the spatial high-pass properties of the surface Laplacian transform may be tailored to the research objective with appropriate parametric adjustments to the CSD algorithm (Kayser and Tenke, 2015b). Importantly, CSD and PCA techniques can be combined to comprehensively identify, summarize, and measure the direction, location, intensity, and timing of current generators underlying scalp-recorded ERPs in an unbiased, data-driven fashion (Kayser and Tenke, 2006a).

The purpose of the present study was to employ this combined CSDPCA approach to 72-channel ERPs recorded during our emotional hemifield paradigm (Kayser and Tenke, 2015a) in a large sample of individuals enrolled in a longitudinal study of family risk for major depression (Weissman et al., 2005). In addition to the data-driven component identification, we used nonparametric permutation tests of the entire topography (Maris, 2004; Kayser and Tenke, 2015a) for an unbiased assessment of emotional effects for relevant CSD-PCA factors. While the primary focus was on an improved characterization of ERP components sensitive to affective stimulus features (i.e., their time course and topographies), this report also sets the stage for addressing whether electrophysiological deficits of emotional processing, as reported for patients with major depression over right temporoparietal regions (e.g., Kayser et al., 2000, 2001; Moratti et al., 2008), are linked to family risk for depression (e.g., Kayser et al., 2014; Moratti et al., 2015). Based on our prior ERP findings with this paradigm, we expected greater scalp current sources for negative compared to neutral stimuli over posterior (i.e., occipital and inferior parietotemporal) sites emerging around $200 \mathrm{~ms}$, with a right-greater-than-left prevalence for a time interval preceding LPP. Furthermore, given the rationale of the visual half-field technique, which presumes that the contralateral afferent projections render privileged (direct) access to the lateralized stimulus presentations (e.g., Springer and Deutsch, 1989), we hypothesized that emotional effects would be enhanced with stimulus exposure to the left hemifield (right hemisphere), particularly for earlier components reflecting processing in extrastriate cortex.

The conceptual validity of the CSD-PCA-based ERP measures was evaluated by determining the linear associations of the mean factor amplitudes with mean valence and arousal ratings obtained from the present sample for these stimuli, hypothesizing that greater ratings of unpleasantness and/or arousal will be linked to greater sink or source activations (e.g., Cuthbert et al., 2000; Schupp et al., 2000).

Finally, we estimated the putative cortical generators underlying CSD components responsive to affective salience using distributed inverse solutions (Pascual-Marqui, 2002). Functional neuroimaging studies have found greater blood oxygen level dependent (BOLD) signal intensity to emotionally arousing as compared to low-arousing neutral IAPS pictures in lateral-occipital, (right) parietal, and inferior-temporal visual cortex (e.g., Bradley et al., 2003; Junghöfer et al., 2006b; Lang et al., 1998b). LPP amplitude has been linked to these differential cortex activations as well as to amygdala, ACC, ventral striatum/nucleus accumbens and anterior insula activations, and the subcortical activations also revealed associations with earlier occipitotemporal ERPs, although less robust compared to the LPP (Sabatinelli et al., 2007, 2013). These neuroimaging findings are in agreement with minimum norm inverse solutions of differential ERP effects (Keil et al., 2002). The extracted CSD-PCA factors were used to quantify consecutive electrophysiological measures of importance for affective stimulus processing. Combined with a strict experimental control of physical stimulus properties, and given the high signal quality resulting from this large sample, we sought to dissect differential cortex activations reflecting "motivated attention" (Bradley et al., 2003) and link their hemispheric asymmetries, if observed, to distinct stages of affective processing in this emotional hemifield paradigm.

\section{Material and methods}

\section{Participants}

The sample consisted of 152 participants ( 71 male) between 13 and 68 years of age (median $=36.5$; mean $\pm S D=35.7 \pm 14.4$ ), most of which ( $n=130$ ) had previously been included in a report focusing on hemifield-dependent N1pc and corresponding theta and delta oscillations during this paradigm (Kayser and Tenke, 2015a). Participants were Caucasian and working or middle class individuals who were enrolled in a multi-generation, 30-year longitudinal study of families at high and low risk for major depression (Weissman et al., 1997, 2005, 2006). For the purpose of this report, family risk status will not be considered further and these findings will be reported elsewhere. As indicated by the laterality quotient of the Edinburgh handedness inventory (Oldfield, 1971), most participants $(n=136)$ were right-handed (median $=85.5$; mean $\pm \mathrm{SD}=85.1 \pm 17.9$ ), with the remaining $11 \%$ of the sample $(n=16)$ being left-handed (median $=-60.0$; mean $\pm S D=-57.8 \pm 31.4$ ), which closely approximates the prevalence of left-handedness in the general population (Peters, 1995). The sample was recruited from an urban setting of the greater New Haven area (Connecticut, US). EEG testing was performed at the Psychophysiology Laboratory at New York State Psychiatric Institute (NYSPI). All procedures were approved by the institutional review boards at Yale University and at Columbia University/NYSPI. All participants gave written informed consent ( $\geq 18$ years) or provided written assent ( $<18$ years; written informed consent from parents).

\section{Stimuli and procedure}

Stimuli were obtained from a textbook of plastic surgery and consisted of 16 closely matched pairs of pictures depicting facial areas of patients with dermatological diseases before (negative) and after (neutral) surgical treatment (Kayser et al., 1997, 2000). As a consequence, neutral stimuli differed from negative stimuli only in the emotionally relevant feature but were virtually identical in all other aspects (i.e., their physical stimulus properties) for any given picture pair. The validity of the emotional construct manipulation via these stimuli was further supported by self-report ratings of pleasantness and skin conductance responses obtained during prior studies, which had revealed the intended, robust distinction between negative and neutral stimuli (Kayser, 1995). This unique stimulus set therefore avoids the potential confounds of non-emotional stimulus characteristics, including content, complexity, or spatial frequency, which have been shown to impact on ERP components (EPN, LPP) indexing affective processing (Delplanque et al., 2007; Wiens et al., 2011).

Using a 20-in. liquid-crystal display (LCD) monitor (resolution $1280 \times 1024$ pixels) placed in a light-dimmed, sound-attenuated IAC (Industrial Acoustics Company) booth, stimuli were presented on a light gray background as digitized images (resolution $182 \times 137$ pixels, 256 colors) to the left or right hemifield. With a chin rest attached to a desk, participants were positioned with their eyes at a constant $57 \mathrm{~cm}$ distance to the surface of the screen. Stimulus presentation subtended visual angles of $7.2^{\circ}$ horizontally, with the outer borders at $\pm 1.7^{\circ}$ and $\pm 8.9^{\circ}$ from fixation in each visual field, and $5.4^{\circ}$ vertically, centered along the fixation horizon marked by a black cross $(20 \times 20$ pixels $)$ in the middle of the screen. Stimulus exposure time was $250 \mathrm{~ms}$. Rapid and predictable stimulus onsets and offsets were coordinated by $\mathrm{STIM}^{2}$ software (NeuroScan, 2003b), as confirmed by direct measurements of a photo resistor attached to the surface of the screen.

Using a pseudo-randomized sequence of four blocks consisting of 32 trials (128 trials total), each stimulus was presented once per block to the left or right visual field. Within every four consecutive trials, each 

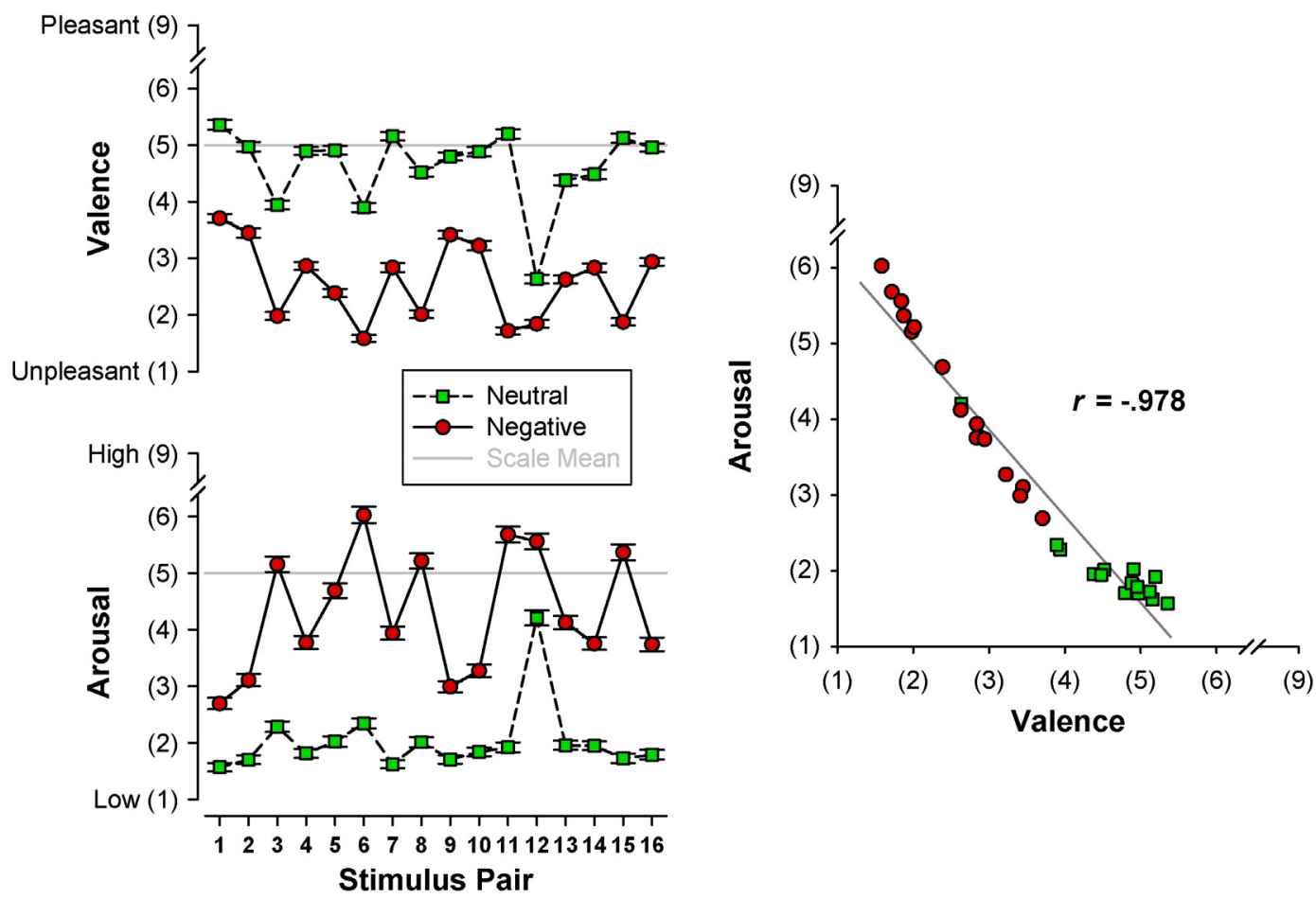

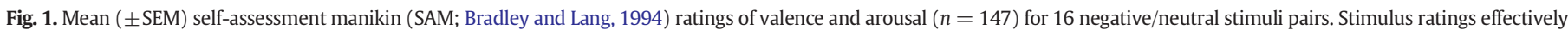
varied linearly along a pseudo dimension ranging from neither-unpleasant-nor-pleasant and not arousing to unpleasant and moderately arousing.

combination of hemifield (left, right) and emotional content (negative, neutral) occurred exactly once, using stimuli from different stimulus pairs and random Latin squares of rank 4. Each participant received a different sequence. Because the affective feature of a particular stimulus was not necessarily in the center of the picture, stimuli were mirrored in blocks 3 and 4 (see Bryson et al., 1991). Stimuli were presented with variable intertrial intervals $(8-13 \mathrm{~s})$. Trials were separated by the temporary disappearance of the fixation cross. Participants were instructed and trained to attend to the stimulus presentations while maintaining fixation, but allowed to relax between trials. No manual response was required.

At the beginning of the emotional hemifield paradigm, horizontal eye movements (saccades) were individually calibrated by prompting participants to alternate their eye focus between the monitor center and the mid-locations for the left and right hemifield presentations.

At the end of the emotional hemifield paradigm, valence and arousal ratings were obtained from most participants $(n=147)$ for 3 -s foveal presentations of these stimuli using a computerized version of the self-assessment manikin (SAM; Bradley and Lang, 1994). Participants indicated on 9-point Likert scales the perceived hedonic value (unpleasant to pleasant) and arousal level (low to high) of each stimulus using a separate, pseudo-randomized sequence of the 64 unique stimuli (i.e., the 16 original stimulus pairs and their mirror counterparts).

\section{Data acquisition, recording, and artifact procedures}

Continuous EEGs were acquired at 1024 samples/s using a 24-bit BioSemi system (BioSemi, Inc., 2001) with a 72-channel 10/10 system scalp montage (Jurcak et al., 2007; Pivik et al., 1993) including the nose (see Fig. 1 of Kayser and Tenke, 2015a). All offline data processing and artifact procedures for this study have been detailed by Kayser and Tenke (2015a), including removal of volume-conducted blink artifacts via spatial singular value decomposition (NeuroScan, 2003a), screening for electrolyte bridges (Alschuler et al., 2014; Tenke and Kayser, 2001), and identification and interpolation of residual EEG artifacts on a channel-by-channel and trial-by-trial basis (Kayser and Tenke, 2006c). Trials in which horizontal eye movements exceeded $2^{\circ}$ from baseline before stimulus onset during stimulus exposure were rejected to preserve the integrity of the visual half-field paradigm. Data of a missing trial within a trial quadruplet (i.e., all four trials of a particular negative/neutral stimulus pair during blocks 1 and 2 or blocks 3 and 4) were estimated via linear interpolation if the other three trials were valid (see Kayser and Tenke, 2015a). This procedure resulted in an equal number of trials to compute ERP averages for each of the four conditions (hemifield $\times$ emotional content), yielding means $( \pm S D)$ of $29.7 \pm 3.3$ (range 14 to 32 , median $=31$ ) trials per condition. ERP waveforms were low-pass filtered at $12.5 \mathrm{~Hz}$ ( $-24 \mathrm{~dB} /$ octave).

\section{Current source density (CSD) and principal components analysis (PCA)}

Using a spherical spline surface Laplacian (Perrin et al., 1989), ERP waveforms were transformed into CSD estimates $\left(\mu \mathrm{V} / \mathrm{cm}^{2}\right.$ units; $10 \mathrm{~cm}$ head radius; 50 iterations; spline flexibility parameter $m=4$; smoothing constant $\lambda=2.5 \times 10^{-5}$; Kayser and Tenke, 2006a, 2006b, 2015b). ${ }^{1}$ In deviation from our previous studies, which employed a default smoothing constant $\left(\lambda=10^{-5}\right)$, an optimized regularization constant was estimated from the observed ERPs for the time interval of interest (200-700 ms), following the proposal by Carvalhaes and de Barros (2015).

As previously detailed (Kayser and Tenke, 2006a), PCA was used to determine the common sources of variance in the CSD waveforms. Data consisted of the samples during the ERP epoch (time interval -200 to $1500 \mathrm{~ms}$ : 1537 variables) for 152 participants, 4 conditions, and 72 electrode sites (43,776 observations). After baseline correction (100 ms prestimulus), data were submitted to a temporal PCA derived from the covariance matrix, followed by unrestricted Varimax rotation of the covariance loadings (Kayser and Tenke, 2003, 2005). ${ }^{2}$ In a

\footnotetext{
1 The CSD toolbox provides a Matlab implementation of these algorithms, which is freely available for download at http://psychophysiology.cpmc.columbia.edu/Software/ CSDtoolbox.

2 The Matlab code (see appendix of Kayser and Tenke, 2003) that emulates BMDP-4M algorithms (Dixon, 1992) for this purpose is available for download at http:// psychophysiology.cpmc.columbia.edu/erpPCA.html.
} 
temporal PCA, the factor loadings reflect the strength of activation over time, whereas amplitude and sign of the factor scores reflect the weight and polarity of a given factor for each observation (Kayser and Tenke, 2003). The goal was to derive unbiased, data-driven, and referencefree component measures in the time domain that effectively characterize differences in emotional content. By virtue of the referenceindependent surface Laplacian transform that counters the problem of signal distortion due to volume conduction (for reviews, see Carvalhaes and de Barros, 2015; Kayser and Tenke, 2015b; Tenke and Kayser, 2012), the temporal CSD factors are associated with factor scores that directly reflect neuronal generator patterns at scalp. Importantly, and in sharp contrast to reference-dependent surface potentials (e.g., Kayser and Tenke, 2010, 2015b), temporal CSD-PCA factors are unambiguous with regard to signal polarity and location, providing not only an enhanced topographical representation but also a better temporal resolution than their ERP counterparts (Burle et al., 2015; Kayser and Tenke, 2006a). Finally, the CSD transformation itself resolves spatial redundancy due to volume conduction (Tenke and Kayser, 2012), a problem that has previously been addressed by employing spatial data decomposition via PCA or independent components analysis (ICA; e.g., Foti et al., 2009; Pourtois et al., 2008; Sato et al., 2001).

\section{Statistical analysis}

CSD-PCA factors were considered for further analysis if a factor explained a sizable amount of variance (>1\%) and factor loadings peaked during the typical 200-700 ms time interval of the N2/P3 complex, thereby aligning with previously identified ERP components for this emotional hemifield paradigm (Kayser et al., 1997, 2000). The experimental effects of primary interest (i.e., emotional content differences in topography) were evaluated by unbiased permutation tests, which do not depend on any auxiliary assumption required for parametric $F$ statistics (Huo et al., 2014; Maris, 2004). ${ }^{3}$

Randomization tests that revealed robust emotional content effects were followed-up by repeated measures ANOVAs with emotional content (negative, neutral) and visual field (left, right) as within-subjects factors. The selection of recording sites included in these ANOVAs was guided by the permutation tests, selecting homologous subsets over both hemispheres where emotional content effects were most robust, thereby adding site and hemisphere as within-subjects factors to the design. However, because recording sites were selected on the premise that they collectively represent radial current flow at scalp reflecting differences of emotional content for a given CSD component, site effects were not further considered in these analyses.

For analyses of the stimulus ratings, the SAM scores for valence and arousal were submitted to separate repeated measures ANOVAs with emotional content (negative, neutral), stimulus orientation (original, mirror), and pair (16) as within-subjects factors.

Gender (male, female) was included but only considered as a control factor for all ANOVA $F$ statistics. When appropriate, Greenhouse-Geisser epsilon $(\varepsilon)$ correction was used to compensate for violations of sphericity (e.g., Keselman, 1998). Sources of interactions and main effects were explored with simple effects (BMDP-4V; Dixon, 1992). A conventional significance level $(p<0.05)$ was applied for all statistical analyses. Effect sizes are reported as partial eta squared $\left(\eta^{2}\right)$.

\footnotetext{
${ }^{3}$ Following our previous implementations of this analytical approach in different ERP contexts (Kayser et al., 2007, 2010, 2013, Kayser and Tenke, 2015a), nonparametric reference distributions were estimated separately for each factor from the observed data by computing the maximum randomization distribution (10,000 repetitions) of the univariate (channel-specific) $T^{2}$ statistic for paired samples (see Eq. 2 in Kayser et al., 2007) jointly for all channels in the EEG montage after randomly multiplying the observed negative/ neutral topographic difference for each participant by +1 or -1 .
}

\section{Distributed inverse solutions of CSD factors}

Standardized low-resolution brain electromagnetic tomography (sLORETA; Pascual-Marqui, 2002), a highly popular distributed inverse algorithm, was employed to obtain an estimate of the putative cortical generators underlying the observed emotional content effects. Because CSD measures, which already represent estimates of radial current flow at scalp, cannot be directly employed for inverse solutions, the CSD-PCA factors were first back-projected into surface potential space using the reference electrode standardization technique (REST) as an estimate of the "infinite" reference (Yao, 2001). ${ }^{4}$ This was accomplished by rescaling the CSD covariance loadings to unit, multiplying the resulting correlation loadings with the variance of each REST variable (i.e., the standard deviation of the ERP time points), and calculating grand mean REST factor scores for negative and neutral stimuli. The difference (negative-minus-neutral) and mean (overall amplitude) were submitted to Brainstorm software (version 3.2; Tadel et al., 2011) to compute unconstrained sLORETA solutions with a boundary element method (BEM) cortex model (OpenMEEG; Gramfort et al., 2010). Given that the PCA factors already reflected optimized CSD component summaries, Brainstorm sLORETA model parameters were restricted to a diagonal noise covariance matrix with an EEG regularization value of 0.1 . Solutions were visualized with Brainstorm's default anatomy derived from an average Montreal Neurological Institute brain template (Collins et al., 1998; Holmes et al., 1998). ${ }^{5}$

\section{Correspondence between CSD factors and ratings of valence and arousal}

As an empirical proof of construct validity, we tested whether the item variance of the electrophysiological and behavioral measures covaried in line with expectations. If the CSD-PCA components reliably reflect the emotional content construct, as operationalized by the 16 negative-neutral stimulus pairs, greater valence and arousal ratings should correspond to greater factor scores. To this end, across-subjects CSDs were computed for each of the 128 trials (32 stimuli $\times 2$ orientations $\times 2$ hemifields). Because of the rejection of trials due to artifacts, a different number of subjects contributed to each acrosssubjects CSD ( $134 \leq n \leq 146)$; however, due to the specific artifact procedures explained above, each subject either contributed all or none of the trials belonging to any given stimulus pair. Factor scores were computed from the across-subjects CSDs by employing the original CSD-PCA factor loadings (Kayser and Tenke, 2003) and then pooled across visual field and stimulus orientation, yielding grand mean factor score topographies for 16 negative and 16 neutral stimuli. Finally, a single summary measure was computed for a given CSD-PCA factor by pooling across the sites included in the corresponding repeated measures ANOVA.

Pearson product-moment correlations were used to evaluate associations between these stimulus-specific grand mean factor scores and the grand mean valence and arousal ratings for all stimuli $(n=32)$,

\footnotetext{
${ }^{4}$ While the transformation to REST as opposed to any other reference scheme (nose, average, etc.) is not a critical step because the inverse solution itself is reference-free (e.g., Michel et al., 2004), ERPs obtained from an EEG montage of low or medium density are less biased by the reference choice when transformed to REST (Kayser and Tenke, 2010, 2015a; Yao et al., 2007), which is a helpful attribute when comparing CSD and ERP waveforms.

${ }^{5}$ We also tested related inverse algorithms as implemented in Brainstorm (depthweighted minimum L2 norm estimation; Hämäläinen and Ilmoniemi, 1994; dynamic statistical parametric mapping; Dale et al., 2000), compared solutions for other constraints of source orientation (normal to cortex, relaxed ['loose'] normal to cortex), used different head models (i.e., three-layer sphere, Berg and Scherg, 1994; OpenMEEG BEM volume; Gramfort et al., 2010) and verified that the Brainstorm sLORETA solution matched the one obtained with of the original sLORETA-KEY software (version 2011-08-04; http:// www.uzh.ch/keyinst/loretaOldy.htm). Although these comparisons yielded the overall impression that solutions were by-and-large fairly comparable, subtle differences were nevertheless observed and parameter choices did impact on the results. However, the chosen unconstrained sLORETA solution with a realistic BEM cortex model was found to be most compatible with the CSD measures, which we had stipulated as a necessary requirement for interpreting any non-unique inverse solution (Tenke and Kayser, 2012).
} 
separately for negative and neutral stimuli $(n=16)$, and for the respective negative-minus-neutral difference. Because of the directed, a priori predictions regarding these relationships, one-tailed significance tests were applied.

\section{Results}

\section{Stimulus ratings}

Fig. 1 (left panel) shows the mean valence and arousal SAM scores for the 16 stimulus pairs, indicating excellent construct validity. Overall, negative compared to neutral stimuli were rated as more unpleasant (mean \pm SD, $2.58 \pm 1.40$ vs. $4.63 \pm 1.52, F_{[1,145]}=877.3, p<0.0001$ ) and more arousing $\left(4.32 \pm 2.36\right.$ vs. $2.03 \pm 1.61, F_{[1,145]}=420.8$, $p<0.0001$ ), suggesting that negative stimuli were perceived as moderately unpleasant and moderately arousing whereas neutral stimuli were seen as neither pleasant or unpleasant and not arousing. Prominent differences were also found across the 16 stimulus pairs, yielding robust main effects (for valence, $F_{[15,2175]}=130.9, p<0.0001, \varepsilon=0.5519$; for arousal, $\left.F_{[15,2175]}=124.3, p<0.0001, \varepsilon=0.4713\right)$ and interaction effects with emotional content (for valence, $F_{[15,2175]}=50.9$, $p<0.0001, \varepsilon=0.8012$; for arousal, $F_{[15,2175]}=61.4, p<0.0001, \varepsilon=$ 0.6907); however, while these effects reveal that the degree of the emotional construct varied between the 16 stimulus pairs, the direction of this manipulation remained stable across pairs for both ratings. Stimulus orientation did not affect these findings (all $F \leq 1.33$, all $p \geq 0.25$ ). For this limited stimulus set, valence and arousal ratings did not vary independently along these two dimensions of affective space but instead spread linearly across a pseudo dimension ranging from neitherunpleasant-nor-pleasant and not arousing to unpleasant and moderately arousing (Fig. 1, right panel).

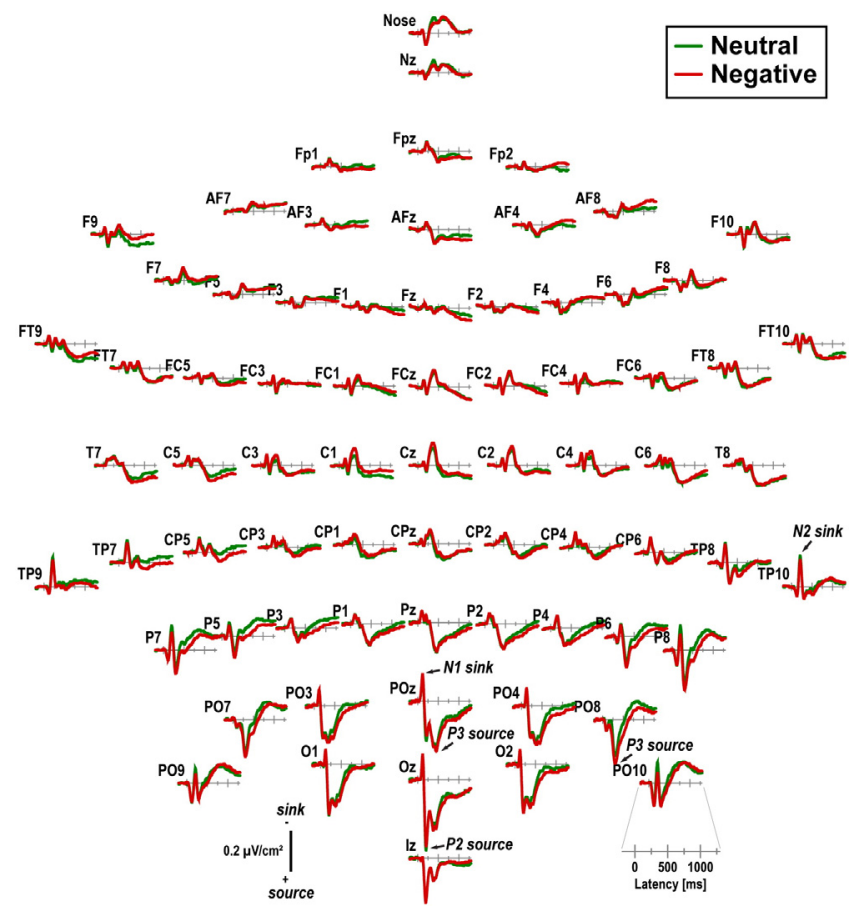

Fig. 2. Grand mean $(N=152)$ current source density $(\mathrm{CSD})\left[\mu \mathrm{V} / \mathrm{cm}^{2}\right]$ waveforms $(-200$ to $1300 \mathrm{~ms}, 100 \mathrm{~ms}$ pre-stimulus baseline) comparing negative and neutral stimuli (pooled across hemifield) at all 72 scalp sites. Distinct CSD components are labeled in italics at selected sites.

\section{Electrophysiological data}

Fig. 2 shows the grand mean CSD waveforms for negative and neutral stimuli, with enlargements of selected medial and lateral parietooccipital sites shown in Fig. 3 (see Supplementary Figs. S1 and S2 for the corresponding ERP waveforms using the reference electrode standardization technique [REST; Yao, 2001] as an estimate of the "infinite" reference). CSDs were characterized by a prominent N1 sink (120 ms peak latency at POz), followed by a P2 source ( $200 \mathrm{~ms}$ at $\mathrm{Oz}$ ) paired with an N2 sink (212 ms at TP10), a P3 source (305 ms at PO8, $450 \mathrm{~ms}$ at POz) paired with a central sink ( $370 \mathrm{~ms}$ at $\mathrm{Cz}$ ), and an extended lateral posterior sink paired with a centroparietal source (beyond $600 \mathrm{~ms}$ ). Differences of emotional content emerged from about $150 \mathrm{~ms}$ on forward, revealing more positive-going CSDs for negative than neutral stimuli at posterior sites. Notably, there was no evidence at lateral posterior sites for an EPN-like component (i.e., more negative-going waveforms for negative compared to neutral stimuli between 200 and $300 \mathrm{~ms}$ ) in CSDs or ERPs, even when transformed to an average reference.

CSDs were also characterized by prominent visual field effects over posterior regions (see Supplementary Figs. S3 and S4), revealing early components (N1 sink, P2 source) exclusively over the contralateral hemisphere (see Kayser and Tenke, 2015a, for a detailed analysis), and a sustained contralateral negativity beyond $400 \mathrm{~ms}$, which has previously been described as an attention-related, hemifield-dependent negativity (HDN; Schweinberger and Sommer, 1991; Schweinberger et al., 1994). As the HDN is superimposed on other ERPs components, largely symmetric and has already been discussed in context of this emotional hemifield paradigm (Kayser et al., 1997), this report will focus on the emotional content effects.

Fig. 4 shows the first seven factor loadings (combined $89.1 \%$ explained variance after rotation, each factor $>1 \%$ ) of the temporal PCA solution (a total of 103 factors were extracted and rotated) and the corresponding factor score topographies of three high-variance factors (>3\%) peaking between 200 and $700 \mathrm{~ms}$. Apart from a distinct medial parietooccipital N1 sink (labeled 124, 2.3\% explained variance; $124 \mathrm{~ms}$ peak latency of factor loading; contralateral maxima at PO3 or PO4, dependent on visual field; cf. Kayser and Tenke, 2015a) and a sustained, long-lasting slow wave $(1287,52.0 \%)$ peaking near the end of the recording epoch that incorporated variance associated with the hemifield-dependent negativity as well as unsystematic variance associated with the autocorrelation of EEG time series data (Kayser and Tenke, 2003), we identified the following factors: (1) a lateral temporoparietal N2 sink paired with a mid-parietooccipital P2 source (212, 5.7\%); (2) a mid-parietal P3 source paired with a mid-central sink (385, 21.2\%); and (3) a centroparietal (CP) source paired with an inferior-lateral parietooccipital sink (630, 4.9\%). Two additional factors reflected sink/ source activation patterns during the transitions from N1 sink to N2 sink (166, 1.3\%) and from N2 sink to P3 source (285, 1.7\%).

Fig. 5 shows the mean factor score topographies of factors 212 (N2 sink), 385 (P3 source) and 630 (CP source) for negative and neutral stimuli, as well as the respective difference topographies and their nonparametric evaluation via randomization tests (see Supplementary Fig. S5 for all seven CSD-PCA factors shown in Fig. 4). Despite distinct differences in overall topography, the emotional content net effect (i.e., negativeminus-neutral) revealed larger posterior sources over parietooccipital regions for negative than neutral stimuli for each of these three consecutive PCA factors. Nevertheless, robustness, extent and asymmetry of these emotional content effects differed. For N2 sink, negative-greaterthan-neutral sources were restricted to lateral-inferior parietooccipital sites (PO9/10, PO7/8, P7/8), which were markedly larger over the right than left hemisphere. These enhancements of sources were accompanied by a relative mid-parietal sink ( $\mathrm{POz}, \mathrm{Pz}$ ), suggesting a dipolar generator involving secondary visual (prestriate) cortex and cuneus. For P3 source, negative-greater-than-neutral sources were rather symmetric and also included adjacent medial parietooccipital sites (PO3/4, P5/6, 01/2). These sources were paired with mid- and medial centroparietal 

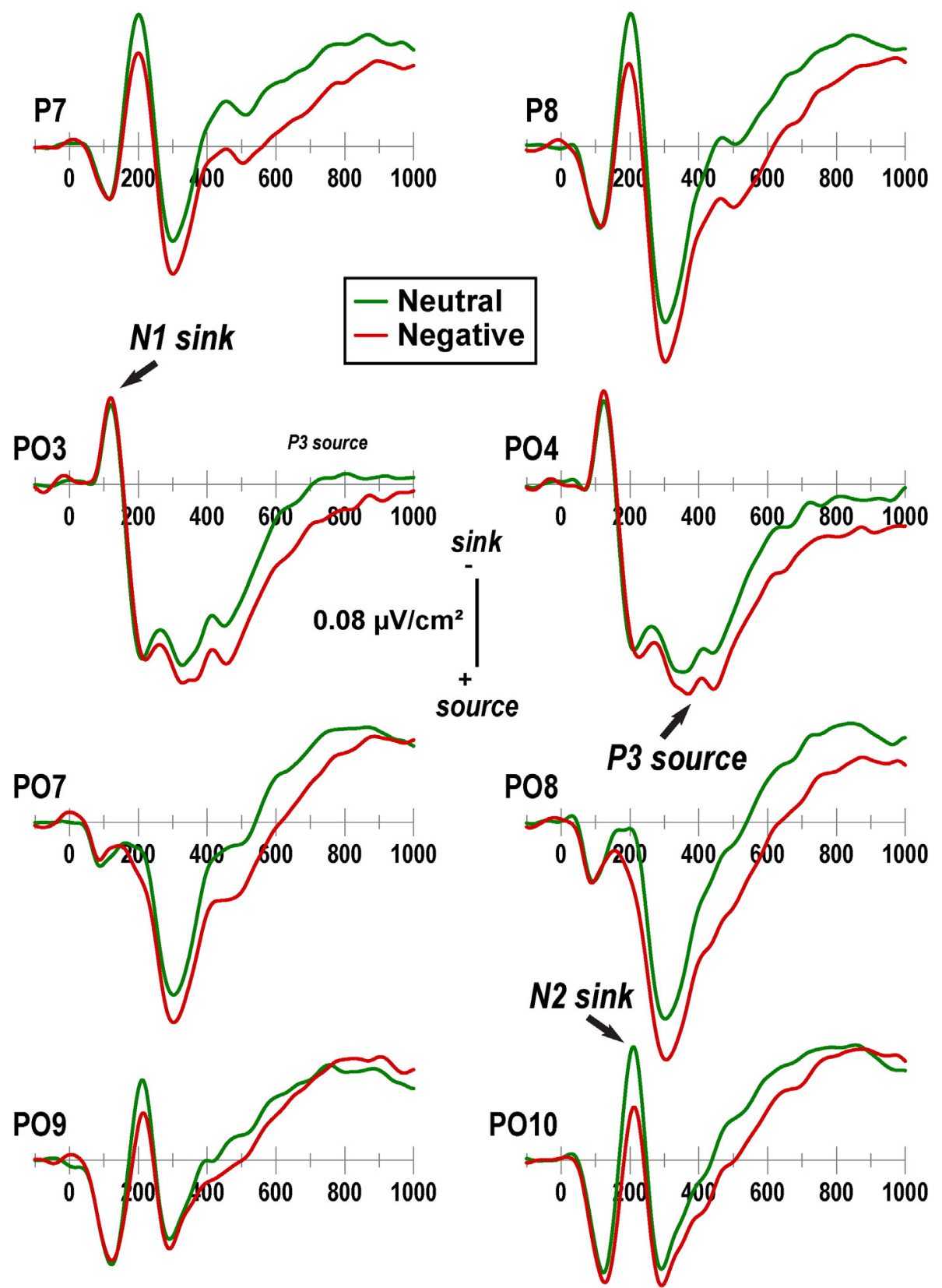

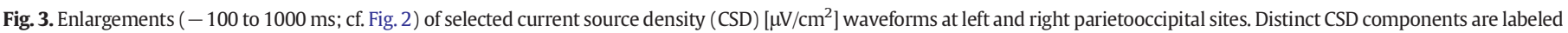
in italics at selected sites.

sinks (CP3, CP1, CPz, C3/4, C1/2, Cz, C6, FC4, FC6), suggesting bihemispheric generators with more anterior orientation. For $\mathrm{CP}$ source, negative-greater-than-neutral sources were less robust than those observed for N2 sink and P3 source, and further expanded the parietooccipital regions to also include centro- and temporoparietal sites over the right hemisphere (CP6, TP8, TP10). These broader emotional content source effects were paired with distant sinks at Nose and FT10.

The parametric evaluations of these effects by means of repeated measures ANOVA, which included hemisphere and hemifield as independent variables, are summarized in Table 1. Given the significant nonparametric findings, N2 sink was probed for three homologous lateral-inferior parietooccipital locations (PO9/10, PO7/8, P7/8), whereas the analyses for $\mathrm{P} 3$ source and $\mathrm{CP}$ source included six parietooccipital pairs (PO9/10, P07/8, P7/8, PO3/4, P5/6, 01/2). These sites are marked as black dots in Fig. 5, with the means for the emotional content $\times$ hemisphere interactions plotted in adjacent line charts. These parametric analyses fully corroborated the nonparametric statistics, showing robust emotional content main effects for all three factors, and a highly significant emotional content $\times$ hemisphere interaction for N2 sink. Simple main effects of emotional content for N2 sink were substantially stronger at the right $\left(F_{[1150]}=61.0, p<0.0001, \eta^{2}=\right.$ $0.2890)$ than left $\left(F_{[1150]}=11.4, p=0.001, \eta^{2}=0.0704\right)$ hemisphere, but were equally robust over both hemispheres for P3 source or $\mathrm{CP}$ source (all $F_{[1150]}>33.2$, all $p<0.0001,0.1813 \leq \eta^{2} \leq 0.2022$ ).

For N2 sink, this two-way interaction was further qualified by a significant emotional content $x$ hemisphere $\times$ visual field interaction, which is simplified in Fig. 5 (top row, last column) by showing the means of the emotional content net effect. For stimuli presented to the left hemifield (LVF), this negative-greater-than-neutral difference was substantially larger over the right than left hemisphere $\left(F_{[1150]}=\right.$ 22.1, $p<0.0001, \eta^{2}=0.1282$ ), whereas the right hemifield (RVF) yielded no significant hemisphere differences $(F<1.0)$. Moreover, the contra- versus ipsilateral stimulation yielded a greater emotional 


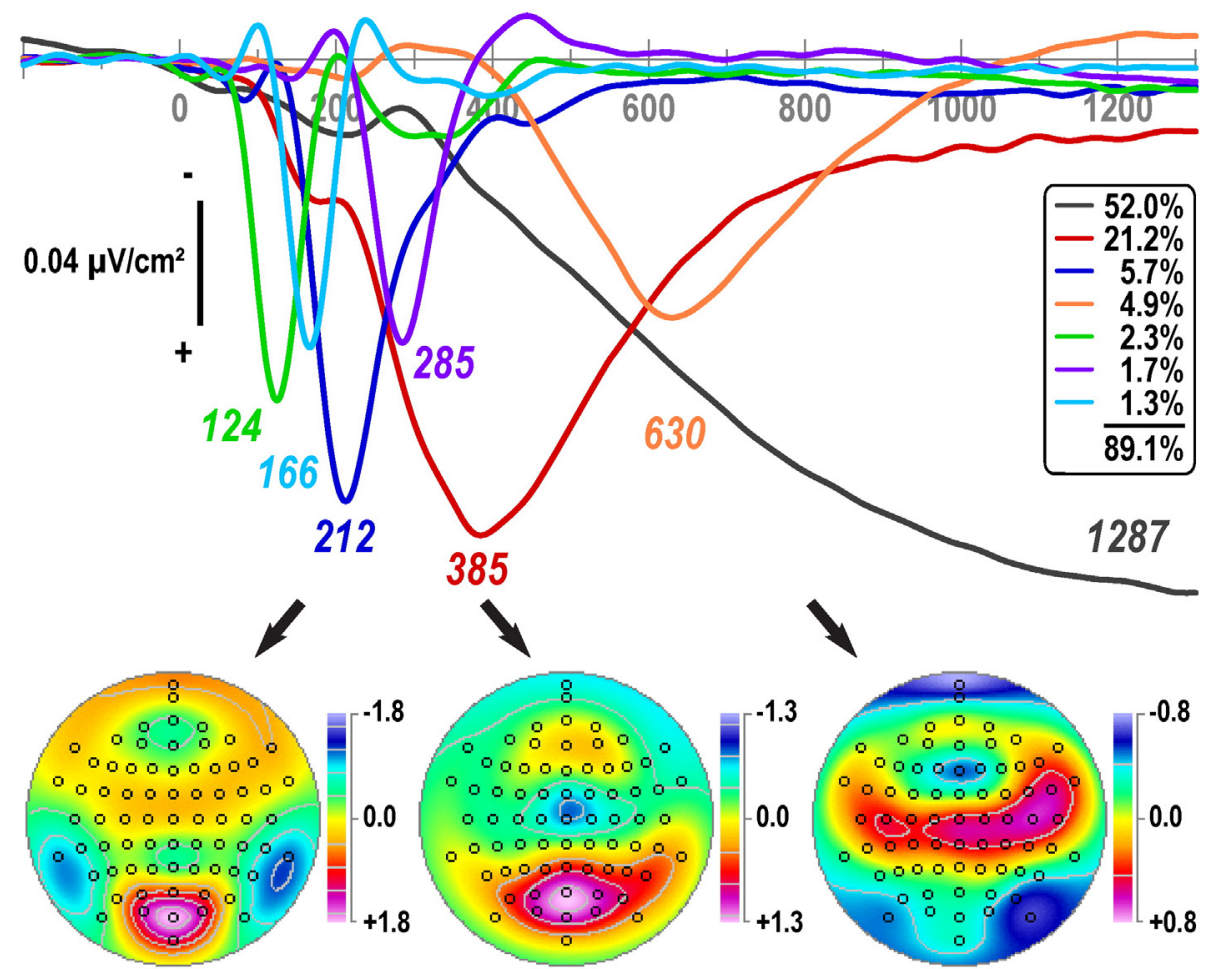

N2 Sink / P2 Source

P3 Source

Centroparietal Source

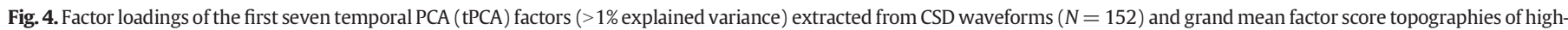
variance factors (>3\%) peaking between 200 and $700 \mathrm{~ms}$. Factor labels reflect the peak latency [ms] of the factor loadings relative to stimulus onset.

content effect for the right hemisphere (LVF $>$ RVF; $F_{[1150]}=12.3, p=$ 0.0006, $\eta^{2}=0.0760$ ) compared to the left hemisphere (RVF > LVF; $\left.F_{[1150]}=4.04, p<0.05, \eta^{2}=0.0262\right)$. A similar, however, weaker emotional content $\times$ hemisphere $\times$ visual field interaction was also found for P3 source due to a robust contralateral enhancement of the emotional content effect for the right hemisphere (LVF > RVF;

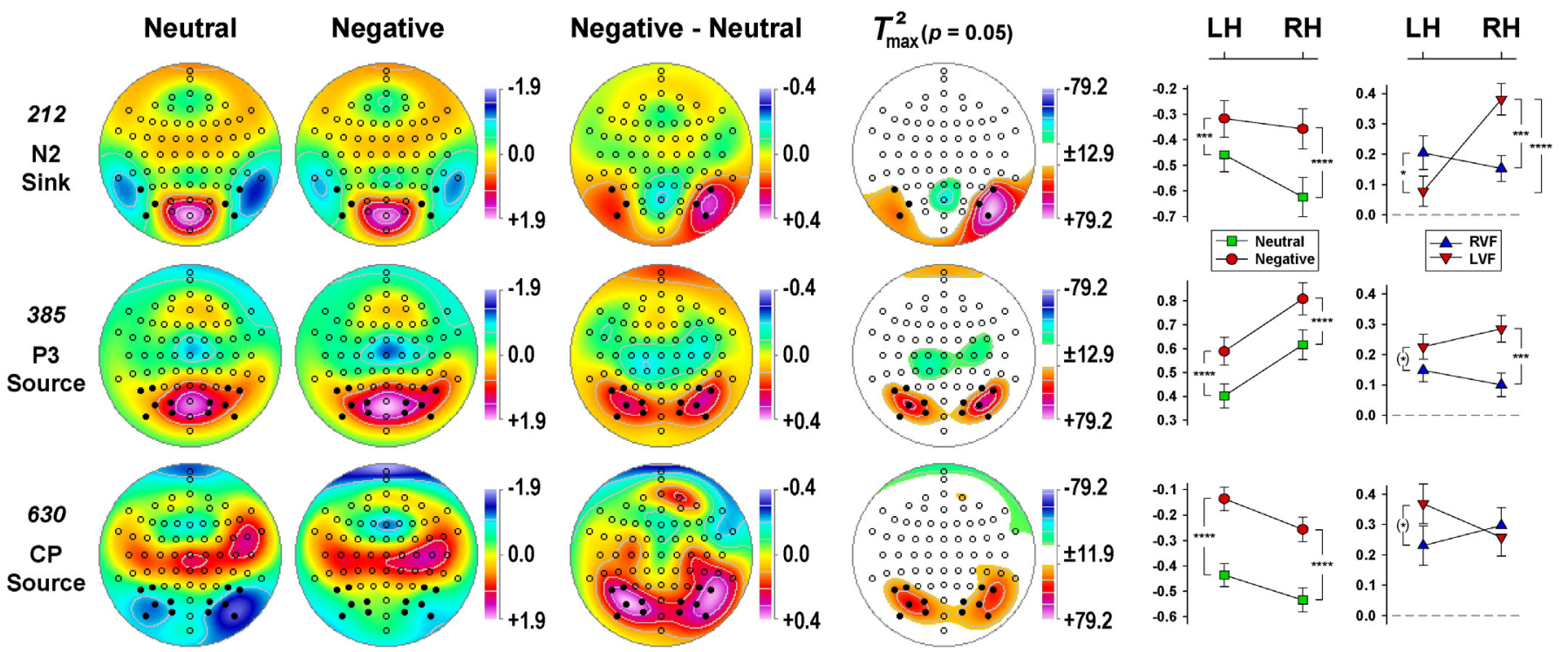

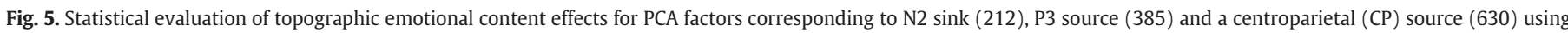

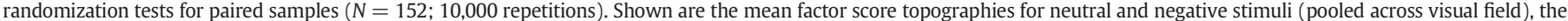

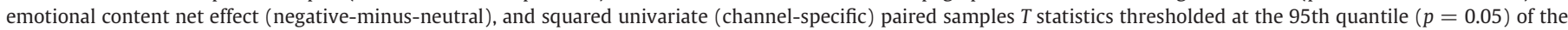

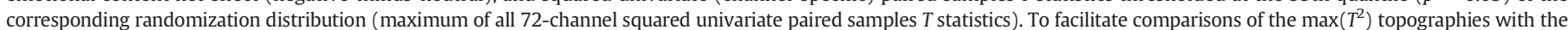

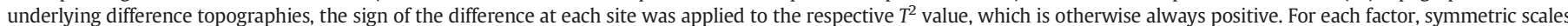

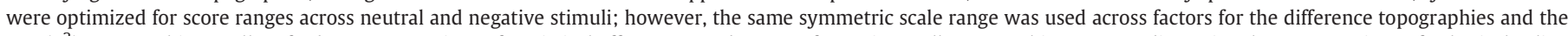

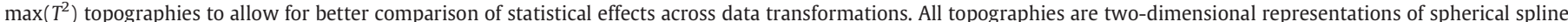

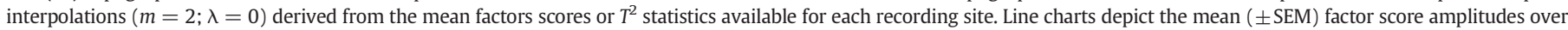

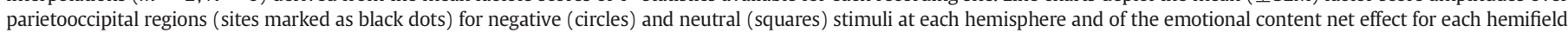
(triangles) at each hemisphere. Significant simple effects are marked as: $\left(^{*}\right) p<0.10 ;{ }^{*} p<0.05 ;{ }^{* * *} p<0.001 ;{ }^{* * * *} p<0.0001$. 
Table 1

Summary of ANOVA $F$ ratios performed on CSD-PCA factors at selected sites.

\begin{tabular}{|c|c|c|c|c|c|c|c|c|c|}
\hline \multirow{5}{*}{$\frac{\mathrm{A}}{\text { Variable }}$} & \multicolumn{9}{|c|}{ Repeated measures designs involving lateral regions over each hemisphere } \\
\hline & \multirow{2}{*}{\multicolumn{3}{|c|}{$\begin{array}{l}212 \\
\text { N2 sink }\end{array}$}} & \multirow{2}{*}{\multicolumn{3}{|c|}{$\begin{array}{l}385 \\
\text { P3 source }\end{array}$}} & \multirow{2}{*}{\multicolumn{3}{|c|}{$\begin{array}{l}630 \\
\text { CP source }\end{array}$}} \\
\hline & & & & & & & & & \\
\hline & \multicolumn{3}{|c|}{$(\mathrm{PO9} / 10, \mathrm{PO} 7 / 8, \mathrm{P} 7 / 8)$} & \multicolumn{6}{|c|}{$(\mathrm{PO} / 10, \mathrm{PO} 7 / 8, \mathrm{P} 7 / 8, \mathrm{PO} / 4, \mathrm{P} 5 / 6,01 / 2)$} \\
\hline & $\bar{F}$ & $p$ & $\eta^{2}$ & $\bar{F}$ & $p$ & $\eta^{2}$ & $F$ & $p$ & $\eta^{2}$ \\
\hline E & 46.9 & $<0.0001$ & 0.2381 & 48.1 & $<0.0001$ & 0.2429 & 49.0 & $<0.0001$ & 0.2463 \\
\hline $\mathrm{E} \times \mathrm{H}$ & 6.89 & 0.01 & 0.0439 & & & & & & \\
\hline $\mathrm{E} \times \mathrm{V}$ & & & & 10.9 & 0.001 & 0.0675 & & & \\
\hline $\mathrm{E} \times \mathrm{H} \times \mathrm{V}$ & 20.4 & $<0.0001$ & 0.1196 & 3.37 & 0.07 & 0.0220 & & & \\
\hline $\mathrm{H}$ & & & & 12.1 & 0.0007 & 0.0747 & 3.91 & 0.05 & 0.0254 \\
\hline $\mathrm{H} \times \mathrm{V}$ & 294.1 & $<0.0001$ & 0.6623 & 255.1 & $<0.0001$ & 0.6297 & 33.5 & $<0.0001$ & 0.1824 \\
\hline V & 14.5 & 0.0002 & 0.0882 & & & & & & \\
\hline
\end{tabular}

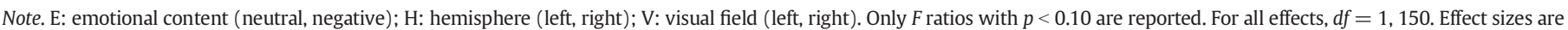
partial eta squared $\left(\eta^{2}\right)$.

$\left.F_{[1150]}=12.0, p=0.0007, \eta^{2}=0.0738\right)$, which was not seen but instead reversed for the left hemisphere $\left(\mathrm{RVF}<\mathrm{LVF} ; F_{[1150]}=2.94, p=0.09\right.$, $\left.\eta^{2}=0.0192\right)$. This left-greater-than-right hemifield emotional content effect for P3 source resulted in a marginally significant emotional content $\times$ visual field interaction (Table 1 ).

As expected, all PCA factors, although to a different degree, revealed strong visual field $\times$ hemisphere effects, due to contralateral hemifield stimulation yielding amplitude enhancements for early components and superimposing a hemifield-dependent negativity on late components (see Supplementary Figs. S3 and S4). Finally, overall N2 sink was greater for right than left hemifield stimulations (mean $\pm S D$, $-0.52 \pm 1.31$ vs. $-0.35 \pm 1.26$ ), overall $\mathrm{P} 3$ source tended to be greater over the right than left hemisphere $(0.71 \pm 1.15$ vs. $0.50 \pm 0.96)$, and the parietooccipital sink that accompanied the overall CP source was greater over the right than left hemisphere $(-0.39 \pm 0.84$ vs. $-0.28 \pm 0.81$; Fig. 4 , bottom row). However, these main effects and hemisphere $\times$ hemifield interactions, which are not dependent on emotional content, are of secondary interest given that sites were deemed optimal for probing emotional content effects but not for measuring overall amplitudes.

\section{Distributed inverse solutions}

Fig. 6 shows the unconstrained sLORETA solutions of the emotional content net effects (negative-minus-neutral) for factors 212 (N2 sink), 385 (P3 source), and 630 (CP source). Static animations of sLORETA solutions for these emotional content effects and for overall factor amplitudes in comparison to the corresponding CSD topographies, as well as for the sLORETA time course of the emotional content effect, are supplied as Supplementary Material (see Animations A1-A3) ${ }^{6}$

These distributed inverse solutions were in close agreement with the differences of emotional content seen for the scalp CSD measures (Fig. 5, columns 3 and 4) and added further clarification regarding their putative generators. N2 sink was linked to asymmetrical sources involving striate and prestriate cortex in the occipital lobe, with a maximum activation in the right middle temporal gyrus (occipitotemporal area, Brodmann area [BA] 37). For P3 source, symmetric inverses involving the medial parietal lobe revealed a maximum activation in the posterior cingulate cortex (dorsal posterior cingulate area, BA 31). CP source was resolved to bilateral generators within the temporal lobe, with a maximum activations in uncus and the inferior temporal area (BA20). Notably, while the emotional content effects roughly paralleled the posterior-to-anterior activation sequence of the components'

\footnotetext{
${ }^{6}$ Interactive animations in Adobe shockwave format can be obtained at URL http:// psychophysiology.cpmc.columbia.edu/ehf2015.html.
}

overall amplitudes via occipital, parietal, and temporal cortex, the specific activations differed nonetheless (see Supplementary Material, Animations A1 and A2). Furthermore, the time course of the emotional content effects revealed distinct distributed inverse maxima at approximately $200 \mathrm{~ms}, 375 \mathrm{~ms}$, and $650 \mathrm{~ms}$, thereby lending further support to the validity of these three PCA factors as manifestations of consecutive stages of emotional processing (see Supplementary Material, Animation A3).

\section{Correlations between CSD components and stimulus ratings}

Scatterplots between grand mean CSD-PCA factor scores and grand mean SAM ratings scores across the 16 negative-neutral stimulus pairs are shown in Fig. 7, with correlation statistics summarized in Table 2. Although to a different degree, all correlations were in the predicted direction (i.e., negative correlations for valence and positive correlations for arousal), indicating that more positive CSD amplitudes at parietooccipital sites were associated with increased ratings of negative valence and greater arousal. Importantly, the separate correlations for negative and neutral stimuli, as well as for their respective differences within each stimulus pair, were comparable in size to the overall correlations including all stimuli, indicating that these effects reflected within- rather than between-category variance of valence and arousal. On a less important note, correlations were fairly parallel in size for valence and arousal ratings, confirming that these two dimensions were not independently varied with this stimulus set, as intended.

\section{Discussion}

The present emotional hemifield paradigm tried to isolate bottom-up processes of "motivated attention" (Bradley et al., 2003) by relying on the intrinsic motivational salience of negative versus neutral stimuli and the hemisphere receiving privileged access to process this information, without interference of cognitive tasks requirements (top-down processes). The CSD findings replicate and extend our prior ERP findings using this paradigm (Kayser et al., 1997, 2000) in several important aspects. First, beginning around $150 \mathrm{~ms}$ after stimulus onset, moderately arousing affective pictures of negative valence generated more positive-going CSD/ERP waveforms over lateral posterior regions when compared to neutral control stimuli closely matched in physical characteristics. This greater positivity was superimposed on the overall CSD/ERP component structure and corresponded to enhanced inferior-lateral parietooccipital sources (i.e., greater radial current flow towards the scalp). However, this extended relative positivity was clearly not a unitary phenomenon originating from occipitotemporal and parietal cortex (Keil et al., 2002) nor a composite of extrastriate occipital, inferior-temporal and medial-parietal cortex (Sabatinelli et al., 2007). Instead, it can be best characterized as a series of distinct, consecutive activations of brain regions along the 


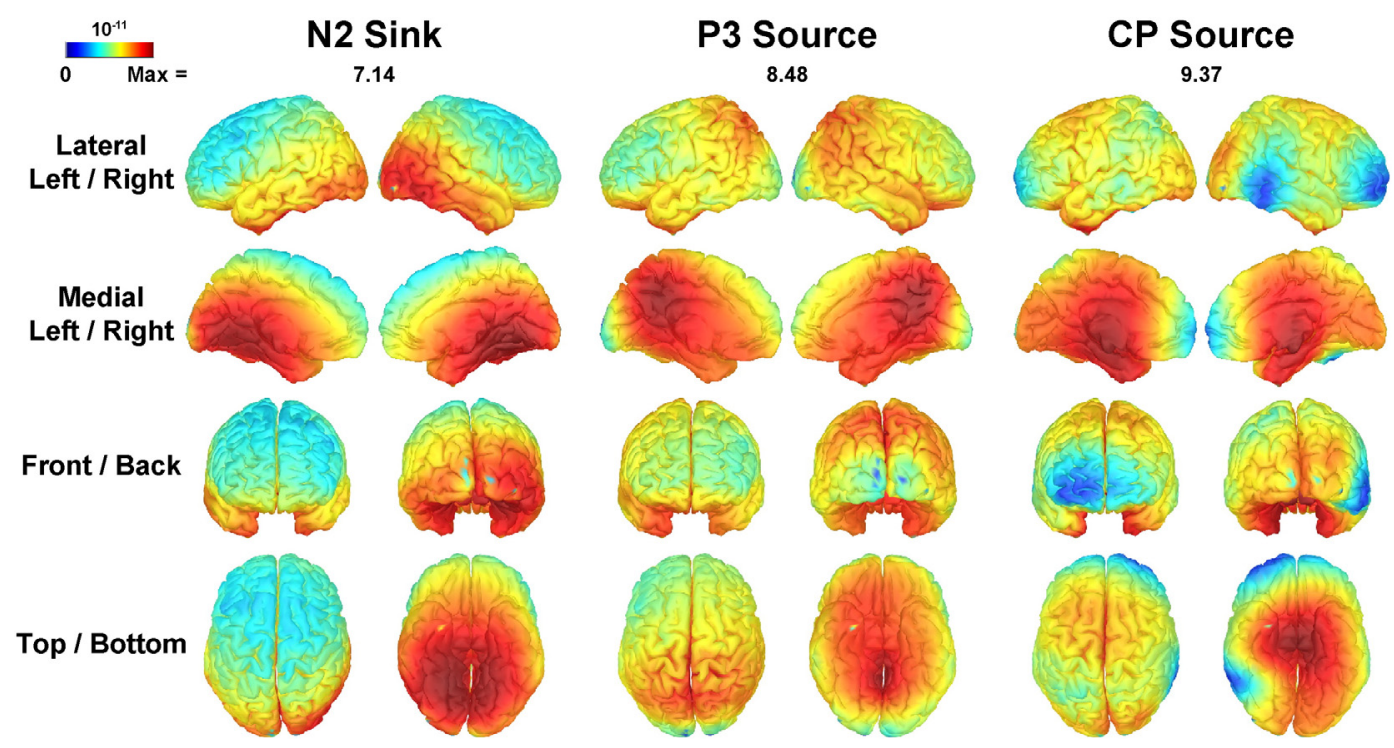

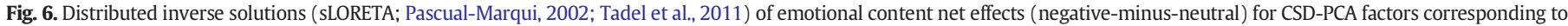
N2 sink (212), P3 source (385), and a centroparietal (CP) source (630). The scale range reflects the overall maximum [(pA/m $\left.)^{1 / 2}\right]$ separately for each factor as indicated.

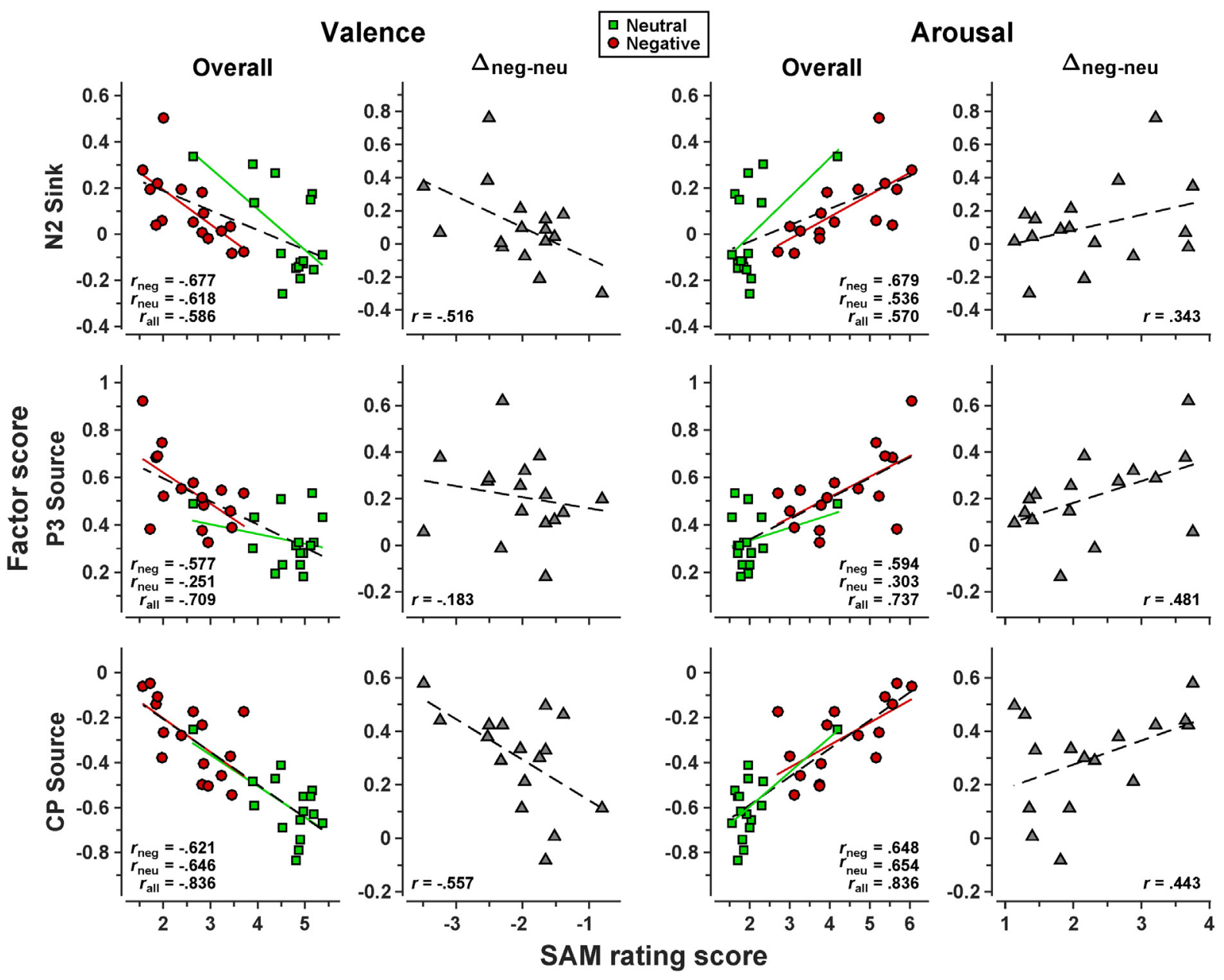

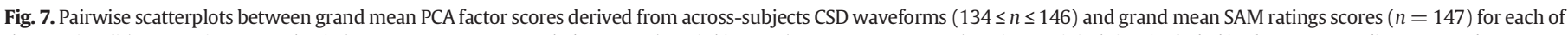

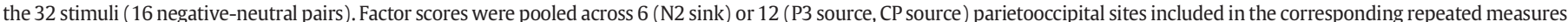

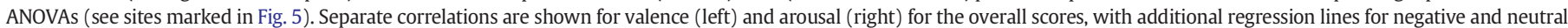

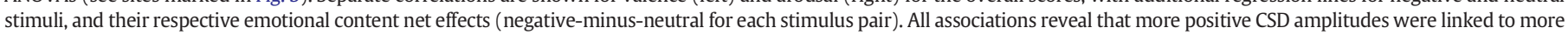
unpleasant and more arousing SAM ratings (see Fig. 1). 
Table 2

Associations between grand mean CSD-PCA factor scores and grand mean SAM ratings scores for 16 negative-neutral stimulus pairs.

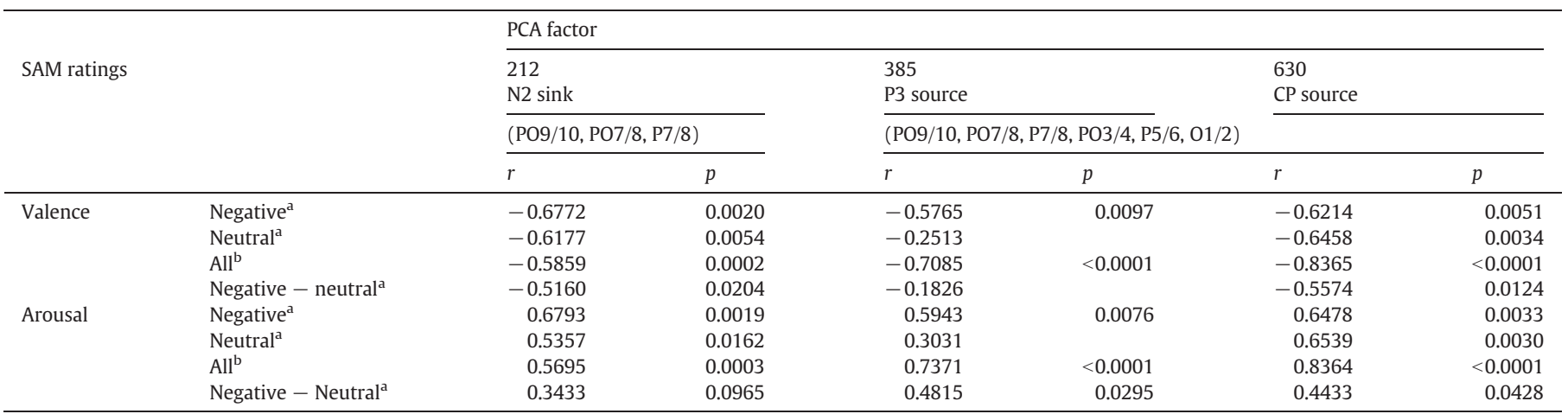

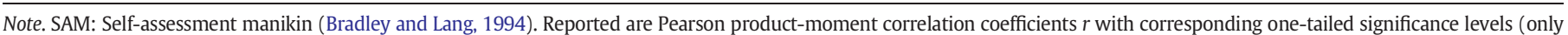
$p<0.10 ; d f=n-2) .{ }^{\mathrm{a}} n=16 ;{ }^{\mathrm{b}} n=32$.

ventral visual pathway involving occipitotemporal, posterior cingulate and inferior temporal cortex. This is consistent with engagement of asymmetric corticolimbic networks during emotional processing (Liotti and Tucker, 1995), involving multiple processing stages with interactions from early visual areas to prefrontal regions (Pessoa, 2008). Increased connectivity between posterior cingulate cortex and ventromedial prefrontal cortex has been hypothesized to play a major role in emotion perception, emotion regulation, self-awareness, and default mode network activity (Gusnard et al., 2001; Li et al., 2014; Lutz et al., 2015; Tang et al., 2015).

Second, the particular role of the right temporoparietal region for detecting affective stimulus significance was confined to an early ERP/ CSD component (N2) that preceded subcomponents of the late positive complex (P3, LPP), presumably originating from asymmetric generator sources in extrastriate cortex (as estimated by sLORETA; PascualMarqui, 2002). Moreover, these asymmetries in affective responsiveness effectively resulted from left hemifield (right hemisphere) presentations, whereas right visual field (left hemisphere) presentations yielded no hemisphere asymmetries in emotional processing. This constitutes a new finding for this emotional hemifield paradigm. Both the considerable statistical power and increased signal-to-noise ratio afforded by the large sample in the present study may have contributed to the emergence of this effect when compared to our prior ERP findings in smaller samples (Kayser et al., 1997), and using a surface Laplacian transform is by far more likely to uncover effects obscured in surface potential measures due to volume conduction (Kayser and Tenke, 2015a). These hemifield-dependent enhancements of early emotional ERPs effects further underscore the importance of the right temporoparietal and occipitotemporal cortex for automatically detecting stimulus salience (Junghöfer et al., 2006b; Keil et al., 2002; Lang et al., 1998b). These effects, which emerge prior to controlled (conscious) stimulus processing, have been regarded as neurophysiological correlates of enhanced attention to motivationally significant stimuli, which is enabled by re-entrant subcortical feedback of anterior brain regions to visual cortex (e.g., Keil et al., 2009, 2012; Moratti et al., 2011; Sabatinelli et al., 2007, 2013). Similar hemifield modulations of emotional effects carried over to P3 source, however, tended to reverse for CP source, but these two later CSD components did not show hemisphere asymmetries in emotional processing.

It is important to recognize that emotional ERP effects for the early $\mathrm{N} 2$ sink factor with its $212 \mathrm{~ms}$ peak latency did reveal opposite effects (i.e., more positive-going ERPs for negative than neutral) than reported for the EPN, which is typically assessed between 200 and $300 \mathrm{~ms}$ (Olofsson et al., 2008). This discrepancy may be closely related to differences in stimuli (i.e., most EPN studies employed IAPS pictures), given that the present stimulus set was highly controlled for physical stimulus characteristics and EPN has been found to vary with differences in stimulus content and may be particularly responsive to pleasant stimuli involving people (Schupp et al., 2004; Weinberg and Hajcak, 2010). However, we should note that a low-variance factor peaking at $285 \mathrm{~ms}$ (Fig. 4) that was not considered further in this report because it lacked robust emotional effects did reveal small emotional effects consistent with EPN activity (see Supplementary Fig. S5, row 4).

Third, the robust associations between all three CSD factors (N2 sink, P3 source, CP source) and ratings of both valence and arousal, which were observed for the individual negative/neutral stimulus pairs using group means, provide strong support for the assertion that relative increases in radial current flow towards the scalp (sources or positivities) reflect facilitation (of motivated attention) across successive, but overlapping, stages of affective processing. While the present experimental design, with a near perfect covariation of unpleasantness and arousal for these stimuli, prevents a dissociation of the relative contribution of valence and arousal characteristics, prior research has convincingly demonstrated that arousal rather than valence is the critical dimension for the observed amplitude enhancements (e.g., Cuthbert et al., 2000; Schupp et al., 2000; see review by Olofsson et al., 2008). Moreover, increased electrodermal activity (EDA) parallels electrocortical activation to emotional pictures (e.g., Keil et al., 2008), as also observed in this emotional hemifield paradigm (Kayser, 2008), which is consistent with phasic EDA being an autonomic index of emotional response intensity (Boucsein, 1995).

Fourth, the present methodological approach of combining referencefree CSD transform and temporal PCA to render component summary measures (Kayser and Tenke, 2006a, 2006b), followed by nonparametric permutation tests to assess topographic differences (Kayser et al., 2007), provides a powerful and effective strategy for uncovering emotional ERP effects in a comprehensive, data-driven fashion. The combined use of CSD components and a distributed inverse algorithm (Pascual-Marqui, 2002; Tadel et al., 2011) represents another step forward in determining the neural generators underlying emotional ERPs and their corresponding scalp current flow. Although all three CSD factors were characterized by prominent emotion-related radial current sources over medial-lateral parietooccipital regions, which corresponded to increased ERP positivity at these sites with an optimized EEG reference (REST; Yao, 2001), these sensor-level findings did not necessarily translate into activations of neuronal tissue located below these scalp sites, which is a common misconception when interpreting surface potential or even surface Laplacian results (e.g., Junghöfer et al., 2006a; Kayser and Tenke, 2015b; Tenke and Kayser, 2012). Instead, and in close correspondence to the complete CSD topographies (Fig. 5) revealing associated sinks over midparietooccipital (N2 sink), medial centroparietal (P3 source) or inferior anterior-lateral sites ( $\mathrm{CP}$ source), the distributed inverses revealed maximum source activations at cortex regions approximately located midway along a dipole bridging source and sink maxima observed at 
scalp. The present approach is likely to provide more reliable inverse solution estimates as they are based on an optimized ERP topography that is (1) known to account for systematic variance and (2) derived from reference-independent scalp activation patterns, thereby counteracting some of the known limitations of EEG source imaging (e.g., Michel et al., 2004) and alleviating concerns regarding uncritically use of these techniques (Tenke and Kayser, 2012).

Fifth, although the current large sample was diverse in the sense that participants were recruited from a multi-generational study of family risk for depression (Weissman et al., 2005), the present findings are in close agreement with those of our prior studies with healthy adults. Therefore, the negative arousal-related emotional ERP effects, which include an early right-greater-than-left asymmetry over occipitotemporal regions that is modulated by hemifield, may be rather universal. However, we and others have found marked reductions of emotional ERP modulations in clinically depressed patients suggesting hypofunction of right temporoparietal regions (e.g., Foti et al., 2010; Kayser et al., 2000, 2001; Moratti et al., 2008), and recent electrophysiologic evidence indicates that blunted responses to emotionally arousing stimuli in major depression may serve as a possible biomarker of treatment success (Domschke et al., 2015; Zwanzger et al., 2016). Moreover, similar electrophysiological deficits may even be present in individuals at high family risk for depression (Moratti et al., 2015), as found with a preliminary analysis for a subsample of this cohort (Kayser et al., 2014). Based on the present findings, a subsequent report will systematically explore the impact of family risk status and personal history of depression and anxiety on these electrophysiological correlates of responsivity to motivationally salient stimuli.

Limitations of this study originate directly from its advantages. First, restricting the stimuli along a single dimension ranging from "not arousing/neutral" to "arousing/negative" does not inform about how appetitive stimuli are processed (Olofsson et al., 2008); however, this stimulus set may isolate aversion or defense as one of the two basic motivational systems (Lang et al., 1998a), and the evaluative space for affective stimuli may be better characterized by a reorientation of valence and arousal dimensions into those representing different degrees of negativity or positivity (Ito et al., 1998a). Second, the passive viewing paradigm did not provide overt performance measures that could be used to validate the theoretical interpretation of the ERP measures and attention to the stimuli (Olofsson et al., 2008). However, employing a visual half-field paradigm serves as an affirmation of attending to stimulus presentation because it renders a contralateral $\mathrm{N} 1 \mathrm{pc}$, which represents a robust early ERP measure of perception and attention (Kayser and Tenke, 2015a; Verleger et al., 2012). In addition, the reported relationship between CSD-PCA factor scores and arousal and valence ratings derived from the present sample discount these objections. More importantly, additional task requirements are likely to engage participants in cognitive operations that may distract from affective processing (e.g., Rozenkrants et al., 2008), down-regulate emotional responses (e.g., Hajcak et al., 2012), or otherwise confound an automatic detection of stimulus salience, all of which may adversely affect hemispheric asymmetries of emotional processing (Kayser et al., 1997). At the same time, overall affective modulation of ERPs has been found to be remarkably robust to various procedural manipulations (e.g., Codispoti et al., 2007, 2012; De Cesarei and Codispoti, 2006, 2008), including foveal versus peripheral (lateralized) stimulus presentations (De Cesarei et al., 2009), suggesting that task-related (topdown) and stimulus-related (bottom-up) effects of motivated attention to stimulus salience are essentially additive (e.g., Hajcak et al., 2012).

\section{Conclusions}

Moderately arousing, unpleasant pictures in comparison to closely matched neutral stimuli evoked a distinct sequence of scalp current sources, beginning with a right-lateralized activation of occipitotemporal cortex that overlapped N2 and peaked at around $200 \mathrm{~ms}$, followed by a bilateral parietal source with a maximum in posterior cingulate cortex that overlapped P3 and peaked around $400 \mathrm{~ms}$, and a bilateral anterior source with a maximum in inferior temporal cortex that overlapped a late centroparietal source and peaked around 600 ms. Early ERP effects of emotional arousal were modulated by hemifield, yielding largest effects (amplitude and asymmetry) for presentations to the left visual field (right hemisphere). These findings are consistent with hierarchical activations of the ventral visual pathway reflecting subsequent processing stages in response to motivationally salient stimuli. As these data were obtained from a large cohort of individuals differing in family risk status for depression, they should provide an excellent opportunity to characterize specific biomarkers of depression risk hypothesized to reflect hypofunction of right temporoparietal cortex.

Supplementary data to this article can be found online at http://dx. doi.org/10.1016/j.neuroimage.2016.05.059.

\section{Competing interests}

None.

\section{Acknowledgments}

This work was supported in part by grant MH036197 from the National Institute of Mental Health (NIMH). We greatly appreciate the use of waveform plotting software written and generously provided by Charles L. Brown, III. We also would like to acknowledge helpful comments and suggestions of two anonymous reviewers.

\section{References}

Alschuler, D.M., Tenke, C.E., Bruder, G.E., Kayser, J., 2014. Identifying electrode bridging from electrical distance distributions: a survey of publicly-available EEG data using a new method. Clin. Neurophysiol. 125 (3), 484-490.

Berg, P., Scherg, M., 1994. A fast method for forward computation of multiple-shell spherical head models. Electroenceph. Clin. Neurophysiol. 90 (1), 58-64.

BioSemi, Inc., 2001. Active Two-Multichannel, DC Amplifier, 24-Bit Resolution, Biopotential Measurement System with Active Electrodes (Http://Www.Biosemi.Com). Author Amsterdam, NL

Boucsein, W., 1995. Die elektrodermale Aktivität als Emotionsindikator. In: Debus, G. Erdmann, G., Kallus, K.W. (Eds.), Biopsychologie von Streß und emotionalen Reaktionen. Hogrefe, Göttingen, pp. 143-161.

Bradley, M.M., 2009. Natural selective attention: orienting and emotion. Psychophysiology 46 (1), 1-11.

Bradley, M.M., Lang, P.J., 1994. Measuring emotion: the self-assessment manikin and the semantic differential. J. Behav. Ther. Exp. Psychiatry 25 (1), 49-59.

Bradley, M.M., Lang, P.J., 2007. The International Affective Picture System (IAPS) in the Study of Emotion and Attention. In: Coan, J.A., Allen, J.J.B. (Eds.), Handbook of Emotion Elicitation and Assessment. Oxford University Press, New York, pp. 29-46.

Bradley, M.M., Sabatinelli, D., Lang, P.J., Fitzsimmons, J.R., King, W., Desai, P., 2003. Activation of the visual cortex in motivated attention. Behav. Neurosci. 117 (2), 369-380.

Bryson, S.E., McLaren, J., Wadden, N.P., MacLean, M., 1991. Differential asymmetries for positive and negative emotion: hemisphere or stimulus effects? Cortex 27 (3), 359-365.

Burle, B., Spieser, L., Roger, C., Casini, L., Hasbroucq, T., Vidal, F., 2015. Spatial and temporal resolutions of EEG: is it really black and white? A scalp current density view. Int J. Psychophysiol. 97 (3), 210-220.

Caltagirone, C., Zoccolotti, P., Originale, G., Daniele, A., Mammucari, A., 1989. Autonomic Reactivity and Facial Expressions of Emotion in Brain-Damaged Patients. In: Gainotti, G., Caltagirone, C. (Eds.), Emotion and the Dual Brain. Springer, Berlin, pp. 204-221.

Campbell, R., 1982. The lateralization of emotion: a critical review. Int. J. Psychophysiol. 17 (2-3), 211-229.

Carvalhaes, C., de Barros, J.A., 2015. The surface Laplacian technique in EEG: theory and methods. Int. J. Psychophysiol. 97 (3), 174-188.

Codispoti, M., Ferrari, V., Bradley, M.M., 2007. Repetition and event-related potentials: distinguishing early and late processes in affective picture perception. J. Cogn. Neurosci. 19 (4), 577-586.

Codispoti, M., De Cesarei, A., Ferrari, V., 2012. The influence of color on emotional perception of natural scenes. Psychophysiology 49 (1), 11-16.

Collins, D.L., Zijdenbos, A.P., Kollokian, V., Sled, J.G., Kabani, N.J., Holmes, C.J.., et al., 1998 Design and construction of a realistic digital brain phantom. IEEE Trans. Med. Imaging 17 (3), 463-468

Corbetta, M., Shulman, G.L., 2002. Control of goal-directed and stimulus-driven attention in the brain. Nat. Rev. Neurosci. 3 (3), 201-215.

Cuthbert, B.N., Schupp, H.T., Bradley, M.M., Birbaumer, N., Lang, P.J., 2000. Brain potentials in affective picture processing: covariation with autonomic arousal and affective report. Biol. Psychol. 52 (2), 95-111. 
Dale, A.M., Liu, A.K., Fischl, B.R., Buckner, R.L., Belliveau, J.W., Lewine, J.D., et al., 2000. Dynamic statistical parametric mapping: combining fMRI and MEG for high-resolution imaging of cortical activity. Neuron 26 (1), 55-67.

Davidson, R.J., 1995. Cerebral Asymmetry, Emotion, and Affective Style. In: Davidson, R.J., Hugdahl, K. (Eds.), Brain Asymmetry. MIT Press, Cambridge, MA, pp. 361-387.

De Cesarei, A., Codispoti, M., 2006. When does size not matter? Effects of stimulus size on affective modulation. Psychophysiology 43 (2), 207-215.

De Cesarei, A., Codispoti, M., 2008. Fuzzy picture processing: effects of size reduction and blurring on emotional processing. Emotion 8 (3), 352-363.

De Cesarei, A., Codispoti, M., Schupp, H.T., 2009. Peripheral vision and preferential emotion processing. Neuroreport 20 (16), 1439-1443.

Delplanque, S., Lavoie, M.E., Hot, P., Silvert, L., Sequeira, H., 2004. Modulation of cognitive processing by emotional valence studied through event-related potentials in humans. Neurosci. Lett. 356 (1), 1-4.

Delplanque, S., Silvert, L., Hot, P., Rigoulot, S., Sequeira, H., 2006. Arousal and valence ef fects on event-related $\mathrm{P} 3 \mathrm{a}$ and $\mathrm{P} 3 \mathrm{~b}$ during emotional categorization. Int. J. Psychophysiol. 60 (3), 315-322.

Delplanque, S., N'diaye, K., Scherer, K., Grandjean, D., 2007. Spatial frequencies or emotional effects? A systematic measure of spatial frequencies for IAPS pictures by a discrete wavelet analysis. J. Neurosci. Methods 165 (1), 144-150.

Demaree, H.A., Everhart, D.E., Youngstrom, E.A., Harrison, D.W., 2005. Brain lateralization of emotional processing: historical roots and a future incorporating "dominance". Behav. Cogn. Neurosci. Rev. 4 (1), 3-20.

Dixon, W.J. (Ed.), 1992. BMDP Statistical Software Manual: To Accompany the 7.0 Software Release. University of California Press, Berkeley, CA.

Domschke, K., Zwanzger, P., Rehbein, M.A., Steinberg, C., Knoke, K., Dobel, C., et al., 2015. Magnetoencephalographic correlates of emotional processing in major depression before and after pharmacological treatment. Int. J. Neuropsychopharmacol. 19 (2), 1-9. http://dx.doi.org/10.1093/ijnp/pyv093.

Donchin, E., Heffley, E.F., 1978. Multivariate Analysis of Event-Related Potential Data: A Tutorial Review. In: Otto, D.A. (Ed.), Multidisciplinary Perspectives in Event-Related Brain Potential Research. Proceedings of the Fourth International Congress on Event-Related Slow Potentials of the Brain (EPIC IV). The Office, Washington, DC, pp. 555-572 (Hendersonville, NC, April 4-10, 1976).

Foti, D., Hajcak, G., Dien, J., 2009. Differentiating neural responses to emotional pictures: evidence from temporal-spatial PCA. Psychophysiology 46 (3), 521-530.

Foti, D., Olvet, D.M., Klein, D.N., Hajcak, G., 2010. Reduced electrocortical response to threatening faces in major depressive disorder. Depress. Anxiety 27 (9), 813-820.

Gainotti, G., 1987. Disorders of Emotional Behaviour and of Autonomic Arousal Resulting from Unilateral Brain Damage. In: Ottoson, D. (Ed.), Duality and Unity of the Brain. Plenum Press, New York, pp. 161-179.

Gainotti, G., 1989. Disorders of Emotions and Affect in Patients with Unilateral Brain Damage. In: Boller, F., Grafman, J. (Eds.), Handbook of Neuropsychology vol. 3. Elsevier, Amsterdam, pp. 345-361.

Gainotti, G., 2015. Implications of recent findings for current cognitive models of familiar people recognition. Neuropsychologia 77, 279-287.

Gramfort, A., Papadopoulo, T., Olivi, E., Clerc, M., 2010. OpenMEEG: opensource software for quasistatic bioelectromagnetics. Biomed. Eng. Online 9 (45), 1-20.

Gusnard, D.A., Akbudak, E., Shulman, G.L., Raichle, M.E., 2001. Medial prefrontal cortex and self-referential mental activity: relation to a default mode of brain function. Proc. Natl. Acad. Sci. U. S. A. 98 (7), 4259-4264.

Hajcak, G., Weinberg, A., MacNamara, A., Foti, D., 2012. ERPs and the Study of Emotion. In: Luck, S.J., Kappenman, E.S. (Eds.), The Oxford Handbook of Event-Related Potentia Components. Oxford University Press, New York, pp. 441-472.

Hämäläinen, M.S., Ilmoniemi, R.J., 1994. Interpreting magnetic fields of the brain: minimum norm estimates. Med. Biol. Eng. Comput. 32 (1), 35-42.

Heller, W., 1993. Neuropsychological mechanisms of individual differences in emotion, personality, and arousal. Neuropsychology 7 (4), 476-489.

Holmes, C.J., Hoge, R., Collins, L., Woods, R., Toga, A.W., Evans, A.C., 1998. Enhancement of MR images using registration for signal averaging. J. Comput. Assist. Tomogr. 22 (2), 324-333.

Huo, M., Heyvaert, M., Van den Noortgate, W., Onghena, P., 2014. Permutation tests in the educational and behavioral sciences: a systematic review. Methodology (Gott) 10 (2), 43-59.

Ito, T.A., Cacioppo, J.T., Lang, P.J., 1998a. Eliciting affect using the International Affective Picture System: trajectories through evaluative space. Personal. Soc. Psychol. Bull. 24 (8), 855-879.

Ito, T.A., Larsen, J.T., Smith, N.K., Cacioppo, J.T., 1998b. Negative information weighs more heavily on the brain: the negativity bias in evaluative categorizations. J. Pers. Soc. Psychol. 75 (4), 887-900.

Johnston, V.S., Miller, D.R., Burleson, M.H., 1986. Multiple P3s to emotional stimuli and their theoretical significance. Psychophysiology 23 (6), 684-694.

Junghöfer, M., Bradley, M.M., Elbert, T.R., Lang, P.J., 2001. Fleeting images: a new look at early emotion discrimination. Psychophysiology 38 (2), 175-178.

Junghöfer, M., Peyk, P., Flaisch, T., Schupp, H.T., 2006a. Neuroimaging methods in affective neuroscience: selected methodological issues. Prog. Brain Res. 156, 123-143.

Junghöfer, M., Sabatinelli, D., Bradley, M.M., Schupp, H.T., Elbert, T.R., Lang, P.J., 2006b. Fleeting images: rapid affect discrimination in the visual cortex. Neuroreport 17 (2), 225-229.

Jurcak, V., Tsuzuki, D., Dan, I., 2007. 10/20, 10/10, and 10/5 systems revisited: their validity as relative head-surface-based positioning systems. Neurolmage 34 (4), $1600-1611$.

Kayser, J., 1995. Hemisphärenunterschiede, Emotion und bilaterale elektrodermale Aktivität: Experimentelle Untersuchungen zur Lateralisation emotionsbegleitende elektrodermaler Reaktionen (Hemispheric differences, emotion, and bilateral electrodermal activity: Experimental studies on the laterality of electrodermal responses comparing emotions). Europäische Hochschulschriften Bd. 513. Peter Lang Frankfurt a.M.

Kayser, J., 2008. Ereignisbezogene elektrodermale und cortikale Indikatoren der Lateralisation von Emotion (Event-related electrodermal and cortical indices of emotional lateralization). In: Janke, W., Schmidt-Daffy, M., Debus, G. (Eds.), Experimentelle Emotionspsychologie: Methodische Ansätze, Probleme und Ergebnisse. (Experimental Psychology of Emotion: Methodological Approaches, Problems and Results). Pabst Science Publishers, Lengerich, pp. 523-545.

Kayser, J., Tenke, C.E., 2003. Optimizing PCA methodology for ERP component identification and measurement: theoretical rationale and empirical evaluation. Clin. Neurophysiol. 114 (12), 2307-2325.

Kayser, J., Tenke, C.E., 2005. Trusting in or breaking with convention: towards a renaissance of principal components analysis in electrophysiology. Clin. Neurophysiol. 116 (8), 1747-1753.

Kayser, J., Tenke, C.E., 2006a. Principal components analysis of Laplacian waveforms as a generic method for identifying ERP generator patterns: I. Evaluation with auditory oddball tasks. Clin. Neurophysiol. 117 (2), 348-368.

Kayser, J., Tenke, C.E., 2006b. Principal components analysis of Laplacian waveforms as a generic method for identifying ERP generator patterns: II. Adequacy of low-density estimates. Clin. Neurophysiol. 117 (2), 369-380.

Kayser, J., Tenke, C.E., 2006c. Electrical distance as a reference-free measure for identifying artifacts in multichannel electroencephalogram (EEG) recordings. Psychophysiology 43, S51.

Kayser, J., Tenke, C.E., 2010. In search of the Rosetta stone for scalp EEG: converging on reference-free techniques. Clin. Neurophysiol. 121 (12), 1973-1975.

Kayser, J., Tenke, C.E., 2015a. Hemifield-dependent N1 and event-related theta/delta oscillations: an unbiased comparison of surface Laplacian and common EEG reference choices. Int. J. Psychophysiol. 97 (3), 258-270.

Kayser, J., Tenke, C.E., 2015b. Issues and considerations for using the scalp surface Laplacian in EEG/ERP research: a tutorial review. Int. J. Psychophysiol. 97 (3), 189-209.

Kayser, J., Tenke, C., Nordby, H., Hammerborg, D., Hugdahl, K., Erdmann, G., 1997. Eventrelated potential (ERP) asymmetries to emotional stimuli in a visual half-field paradigm. Psychophysiology 34 (4), 414-426.

Kayser, J., Bruder, G.E., Tenke, C.E., Stewart, J.E., Quitkin, F.M., 2000. Event-related potentials (ERPs) to hemifield presentations of emotional stimuli: differences between depressed patients and healthy adults in P3 amplitude and asymmetry. Int. J. Psychophysiol. 36 (3), 211-236.

Kayser, J., Tenke, C.E., Bhattacharya, N., Stewart, J., Quitkin, F., Bruder, G.E., 2001. Eventrelated potentials (ERPs) in depressed patients and healthy adults during hemifield presentations of emotional stimuli: a replication. Psychophysiology 38, S54.

Kayser, J., Tenke, C.E., Gates, N.A., Bruder, G.E., 2007. Reference-independent ERP old/new effects of auditory and visual word recognition memory: joint extraction of stimulusand response-locked neuronal generator patterns. Psychophysiology 44 (6), 949-967.

Kayser, J., Tenke, C.E., Kroppmann, C.J., Fekri, S., Alschuler, D.M., Gates, N.A., et al., 2010. Current source density (CSD) old/new effects during recognition memory for words and faces in schizophrenia and in healthy adults. Int. J. Psychophysiol. 75 (2), 194-210.

Kayser, J., Tenke, C.E., Kroppmann, C.J., Alschuler, D.M., Ben-David, S., Fekri, S., et al., 2013. Olfaction in the psychosis prodrome: electrophysiological and behavioral measures of odor detection. Int. J. Psychophysiol. 90 (2), 190-206.

Kayser, J., Tenke, C.E., Abraham, K., Alschuler, D.M., Alvarenga, J.E., Skipper, J., et al., 2014. Event-related potential (ERP) asymmetries to hemifield presentations of emotional stimuli differ between individuals at high and low risk for major depression. Biol. Psychiatry 73, 151S-152S

Keil, A., Müller M.M., Gruber, T. Wienbruch, C. Stolarova, M., Elbert, T, 2001. Effects of emotional arousal in the cerebral hemispheres: a study of oscillatory brain activity and event-related potentials. Clin. Neurophysiol. 112 (11), 2057-2068.

Keil, A., Bradley, M.M., Hauk, O., Rockstroh, B., Elbert, T., Lang, P.J., 2002. Large-scale neural correlates of affective picture processing. Psychophysiology 39 (5), 641-649.

Keil, A., Smith, J.C., Wangelin, B.C., Sabatinelli, D., Bradley, M.M., Lang, P.J., 2008. Electrocortical and electrodermal responses covary as a function of emotional arousal: a single-trial analysis. Psychophysiology 45 (4), 516-523.

Keil, A., Sabatinelli, D., Ding, M., Lang, P.J., Ihssen, N., Heim, S., 2009. Re-entrant projections modulate visual cortex in affective perception: evidence from Granger causality analysis. Hum. Brain Mapp. 30 (2), 532-540.

Keil, A., Costa, V., Smith, J.C., Sabatinelli, D., McGinnis, E.M., Bradley, M.M., et al., 2012. Tagging cortical networks in emotion: a topographical analysis. Hum. Brain Mapp. 33 (12), 2920-2931.

Keselman, H.J., 1998. Testing treatment effects in repeated measures designs: an update for psychophysiological researchers. Psychophysiology 35 (4), 470-478.

Lang, P.J., Bradley, M.M., Cuthbert, B.N., 1998a. Emotion, motivation, and anxiety: brain mechanisms and psychophysiology. Biol. Psychiatry 44 (12), 1248-1263.

Lang, P.J., Bradley, M.M., Fitzsimmons, J.R., Cuthbert, B.N., Scott, J.D., Moulder, B., et al., 1998b. Emotional arousal and activation of the visual cortex: an fMRI analysis. Psychophysiology 35 (2), 199-210.

Lang, P.J., Bradley, M.M., Cuthbert, B.N., 2005. International Affective Picture System (IAPS): Affective Ratings of Pictures and Instruction Manual (Technical Report A-6). University of Florida, Gainesville, FL.

LeDoux, J.E., 1989. Cognitive-emotional interactions in the brain. Cognit. Emot. 3, 267-289.

Li, W., Mai, X., Liu, C., 2014. The default mode network and social understanding of others: what do brain connectivity studies tell us. Front. Hum. Neurosci. 8, 74

Lindell, A.K., 2013. Continuities in emotion lateralization in human and non-human primates. Front. Hum. Neurosci. 7, 464. 
Liotti, M., Tucker, D.M., 1995. Emotion in Asymmetric Corticolimbic Networks. In: Davidson, R.J., Hugdahl, K. (Eds.), Brain Asymmetry. MIT Press, Cambridge, MA, pp. 389-423.

Lutz, A., Jha, A.P., Dunne, J.D., Saron, C.D., 2015. Investigating the phenomenological matrix of mindfulness-related practices from a neurocognitive perspective. Am. Psychol. 70 (7), 632-658

Maris, E., 2004. Randomization tests for ERP topographies and whole spatiotemporal data matrices. Psychophysiology 41 (1), 142-151.

Mavratzakis, A., Herbert, C., Walla, P., 2016. Emotional facial expressions evoke faster orienting responses, but weaker emotional responses at neural and behavioural levels compared to scenes: a simultaneous EEG and facial EMG study. Neurolmage 124 (A), 931-946.

McKeever, W.F., 1986. Tachistoscopic Methods in Neuropsychology. In: Hannay, J.H. (Ed.), Experimental Techniques in Human Neuropsychology. Oxford University Press, New York, pp. 167-211.

Michel, C.M., Murray, M.M., Lantz, G., Gonzalez, S., Spinelli, L., Grave de Peralta, R., 2004 EEG source imaging. Clin. Neurophysiol. 115 (10), 2195-2222.

Moratti, S., Rubio, G., Campo, P., Keil, A., Ortiz, T., 2008. Hypofunction of right temporoparietal cortex during emotional arousal in depression. Arch. Gen. Psychiatry 65 (5), 532-541.

Moratti, S., Saugar, C., Strange, B.A., 2011. Prefrontal-occipitoparietal coupling underlies late latency human neuronal responses to emotion. J. Neurosci. 31 (47), 17278-17286.

Moratti, S., Strange, B., Rubio, G., 2015. Emotional arousal modulation of right temporoparietal cortex in depression depends on parental depression status in women: first evidence. J. Affect. Disord. 178, 79-87.

NeuroScan, Inc., 2003a. SCAN 4.3-Vol. II. EDIT 4.3-Offline Analysis of Acquired Data (Document number 2203, Revision D). Compumedics Neuroscan, El Paso, TX.

NeuroScan, Inc., 2003b. STIM ${ }^{2}$ User Guide (Document number 9027, Revision A). Compumedics Neuroscan, El Paso, TX.

Nunez, P.L., Srinivasan, R., 2006. Electric Fields of the Brain: The Neurophysics of EEG. Oxford University Press, New York.

Oldfield, R.C., 1971. The assessment and analysis of handedness: the Edinburgh inventory. Neuropsychologia 9 (1), 97-113.

Olofsson, J.K., Nordin, S., Sequeira, H., Polich, J., 2008. Affective picture processing: an integrative review of ERP findings. Biol. Psychol. 77 (3), 247-265.

Pascual-Marqui, R.D., 2002. Standardized low-resolution brain electromagnetic tomography (sLORETA): technical details. Methods Find. Exp. Clin. Pharmacol. 24, 5-12.

Perrin, F., Pernier, J., Bertrand, O., Echallier, J.F., 1989. Spherical splines for scalp potential and current density mapping [corrigenda EEG 02274, EEG Clin. Neurophysiol., 1990, 76, 565]. Electroencephalogr. Clin. Neurophysiol. 72 (2), 184-187.

Pessoa, L., 2008. On the relationship between emotion and cognition. Nat. Rev. Neurosci. 9 (2), 148-158.

Peters, M., 1995. Handedness and its Relation to Other Indices of Cerebral Lateralization. In: Davidson, R.J., Hugdahl, K. (Eds.), Brain Asymmetry. MIT Press, Cambridge, MA, pp. 183-214.

Pivik, R.T., Broughton, R.J., Coppola, R., Davidson, R.J., Fox, N., Nuwer, M.R., 1993. Guidelines for the recording and quantitative analysis of electroencephalographic activity in research contexts. Psychophysiology 30 (6), 547-558.

Pizzagalli, D., Regard, M., Lehmann, D., 1999. Rapid emotional face processing in the human right and left brain hemispheres: an ERP study. Neuroreport 10 (13), 2691-2698.

Pourtois, G., Delplanque, S., Michel, C., Vuilleumier, P., 2008. Beyond conventional eventrelated brain potential (ERP): exploring the time-course of visual emotion processing using topographic and principal component analyses. Brain Topogr. 20 (4), 265-277.

Rozenkrants, B., Olofsson, J.K., Polich, J., 2008. Affective visual event-related potentials: arousal, valence, and repetition effects for normal and distorted pictures. Int. J. Psychophysiol. 67 (2), 114-123.

Sabatinelli, D., Lang, P.J., Keil, A., Bradley, M.M., 2007. Emotional perception: correlation of functional MRI and event-related potentials. Cereb. Cortex 17 (5), 1085-1091.

Sabatinelli, D., Keil, A., Frank, D.W., Lang, P.J., 2013. Emotional perception: correspondence of early and late event-related potentials with cortical and subcortical functional MRI. Biol. Psychol. 92 (3), 513-519.

Sato, W., Kochiyama, T., Yoshikawa, S., Matsumura, M., 2001. Emotional expression boosts early visual processing of the face: ERP recording and its decomposition by independent component analysis. Neuroreport 12 (4), 709-714.

Schupp, H.T., Cuthbert, B.N., Bradley, M.M., Cacioppo, J.T., Ito, T., Lang, P.J., 2000. Affective picture processing: the late positive potential is modulated by motivational relevance. Psychophysiology 37 (2), 257-261.
Schupp, H.T., Junghöfer, M., Weike, A.I., Hamm, A.O., 2003a. Emotional facilitation of sensory processing in the visual cortex. Psychol. Sci. 14 (1), 7-13.

Schupp, H.T., Junghöfer, M., Weike, A.I., Hamm, A.O., 2003b. Attention and emotion: an ERP analysis of facilitated emotional stimulus processing. Neuroreport 14 (8), 1107-1110.

Schupp, H.T., Öhman, A., Junghöfer, M., Weike, A.I., Stockburger, J., Hamm, A.O., 2004. The facilitated processing of threatening faces: an ERP analysis. Emotion 4 (2), 189-200.

Schweinberger, S.R., Sommer, W., 1991. Contributions of stimulus encoding and memory search to right hemisphere superiority in face recognition: behavioural and electrophysiological evidence. Neuropsychologia 29 (5), 389-413.

Schweinberger, S.R., Sommer, W., Stiller, R.M., 1994. Event-related potentials and models of performance asymmetries in face and word recognition. Neuropsychologia 32 (2), $175-191$.

Smith, N.K., Cacioppo, J.T., Larsen, J.T., Chartrand, T.L., 2003. May I have your attention, please: electrocortical responses to positive and negative stimuli. Neuropsychologia 41 (2), 171-183.

Springer, S.P., Deutsch, G., 1989. Left Brain, Right Brain. third ed. Freeman \& Company, San Francisco.

Tadel, F., Baillet, S., Mosher, J.C., Pantazis, D., Leahy, R.M., 2011. Brainstorm: a user-friendly application for MEG/EEG analysis. Comput. Intell. Neurosci. 879716, 1-13.

Tang, Y.Y., Holzel, B.K., Posner, M.I., 2015. The neuroscience of mindfulness meditation. Nat. Rev. Neurosci. 16 (4), 213-225.

Tenke, C.E., Kayser, J., 2001. A convenient method for detecting electrolyte bridges in multichannel electroencephalogram and event-related potential recordings. Clin. Neurophysiol. 112 (3), 545-550.

Tenke, C.E., Kayser, J., 2012. Generator localization by current source density (CSD): implications of volume conduction and field closure at intracranial and scalp resolutions. Clin. Neurophysiol. 123 (12), 2328-2345.

Thom, N., Knight, J., Dishman, R., Sabatinelli, D., Johnson, D.C., Clementz, B., 2014. Emotional scenes elicit more pronounced self-reported emotional experience and greater EPN and LPP modulation when compared to emotional faces. Cogn. Affect. Behav. Neurosci. 14 (2), 849-860.

Tranel, D., Damasio, H., 1994. Neuroanatomical correlates of electrodermal skin conductance responses. Psychophysiology 31 (5), 427-438.

Ungerleider, L.G., Haxby, J.V., 1994. 'What' and 'where' in the human brain. Curr. Opin. Neurobiol. 4 (2), 157-165.

Verleger, R., Zurawska Vel Grajewska, B., Jaskowski, P., 2012. Time-course of hemispheric preference for processing contralateral relevant shapes: P1pc, N1pc, N2pc, N3pc. Adv. Cogn. Psychol. 8 (1), 19-28.

Weinberg, A., Hajcak, G., 2010. Beyond good and evil: the time-course of neural activity elicited by specific picture content. Emotion 10 (6), 767-782.

Weissman, M.M., Warner, V., Wickramaratne, P., Moreau, D., Olfson, M., 1997. Offspring of depressed parents. 10 years later. Arch. Gen. Psychiatry 54 (10), 932-940.

Weissman, M.M., Wickramaratne, P., Nomura, Y., Warner, V., Verdeli, H., Pilowsky, D.J., et al., 2005. Families at high and low risk for depression: a 3-generation study. Arch. Gen. Psychiatry 62 (1), 29-36.

Weissman, M.M., Wickramaratne, P., Nomura, Y., Warner, V., Pilowsky, D., Verdeli, H 2006. Offspring of depressed parents: 20 years later. Am. J. Psychiatry 163 (6), 1001-1008.

Wiens, S., Sand, A., Olofsson, J.K., 2011. Nonemotional features suppress early and enhance late emotional electrocortical responses to negative pictures. Biol. Psychol. 86 (1), 83-89.

Yao, D., 2001. A method to standardize a reference of scalp EEG recordings to a point at infinity. Physiol. Meas. 22 (4), 693-711.

Yao, D., Wang, L., Arendt-Nielsen, L., Chen, A.C., 2007. The effect of reference choices on the spatio-temporal analysis of brain evoked potentials: the use of infinite reference. Comput. Biol. Med. 37 (11), 1529-1538.

Young, A.W., 1982. Methodological and Theoretical Bases of Visual Hemifield Studies. In: Beaumont, J.D. (Ed.), Divided Visual Field Studies of Cerebral Organization. Academic Press, London, pp. 11-27.

Zwanzger, P., Klahn, A.L., Arolt, V., Ruland, T. Zavorotnyy, M., Salzer, J., et al., 2016. Impact of electroconvulsive therapy on magnetoencephalographic correlates of dysfunctional emotional processing in major depression. Eur. Neuropsychopharmacol. 26 (4) 684-692. 